\title{
Unctio : la peinture comme sacrement dans la Pietà de Giovanni Bellini à la Pinacothèque Vaticane
}

Unctio: Painting as Sacrament in Giovanni Bellini's Pietà in Vaticano

Vicki-Marie Petrick

\section{OpenEdition}

1 Journals

Édition électronique

URL : http://journals.openedition.org/imagesrevues/1899

DOI : 10.4000/imagesrevues.1899

ISSN : 1778-3801

Éditeur :

Centre d'Histoire et Théorie des Arts, Groupe d'Anthropologie Historique de l'Occident Médiéval, Laboratoire d'Anthropologie Sociale, UMR 8210 Anthropologie et Histoire des Mondes Antiques

\section{Référence électronique}

Vicki-Marie Petrick, «Unctio : la peinture comme sacrement dans la Pietà de Giovanni Bellini à la Pinacothèque Vaticane », Images Re-vues [En ligne], 10 | 2012, mis en ligne le 14 octobre 2012, consulté le 04 mars 2021. URL : http://journals.openedition.org/imagesrevues/1899 ; DOI : https:// doi.org/10.4000/imagesrevues.1899

Ce document a été généré automatiquement le 4 mars 2021

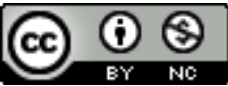

Images Re-vues est mise à disposition selon les termes de la Licence Creative Commons Attribution Pas d'Utilisation Commerciale 4.0 International. 


\title{
Unctio : la peinture comme sacrement dans la Pietà de Giovanni Bellini à la Pinacothèque Vaticane
}

Unctio: Painting as Sacrament in Giovanni Bellini's Pietà in Vaticano

\author{
Vicki-Marie Petrick
}

$\mathrm{Au}$ cours des années 1470-75, Giovanni Bellini crée un retable pour l'église de San Francesco à Pesaro, dans les Marches (fig. $1)^{1}$. Pour qui s'intéresse à la peinture vénitienne dans la seconde moitié du Quattrocento, le retable donne ample matière à réflexion. Les hypothèses concernant sa datation, sa technique, ou les circonstances de sa commande, éclipsent celles de son contenu. La structure même du retable suscite des problèmes : le Couronnement, reposant sur une prédelle historiée et encadré de saints, devait comporter comme de coutume une cimaise avec une Pietà. La question de savoir si le panneau de la Pinacothèque Vaticane représentant le

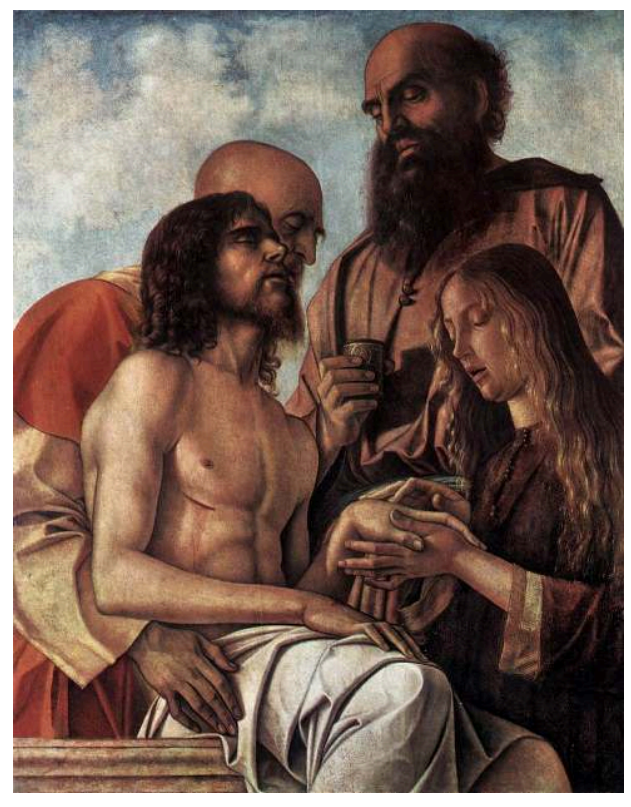
Christ mort entouré de Marie-Madeleine, Joseph d'Arimathie et Nicodème (fig. 2) constituait cette cimaise a longtemps fait débat. À ce jour, outre quelques contributions éparses, la thèse de doctorat de Carolyn Wilson ${ }^{2}$ reste l'étude la plus complète. Celle-ci se concentre sur l'ensemble resté à Pesaro, examinant minutieusement les indices pour en venir à une compréhension synthétique de l'œuvre. Elle s'intéresse au panneau du Vatican, mais les hésitations persistantes 
quant à son appartenance à la structure d'origine entravaient nécessairement toute interprétation contextuelle poussée.

Fig. 1

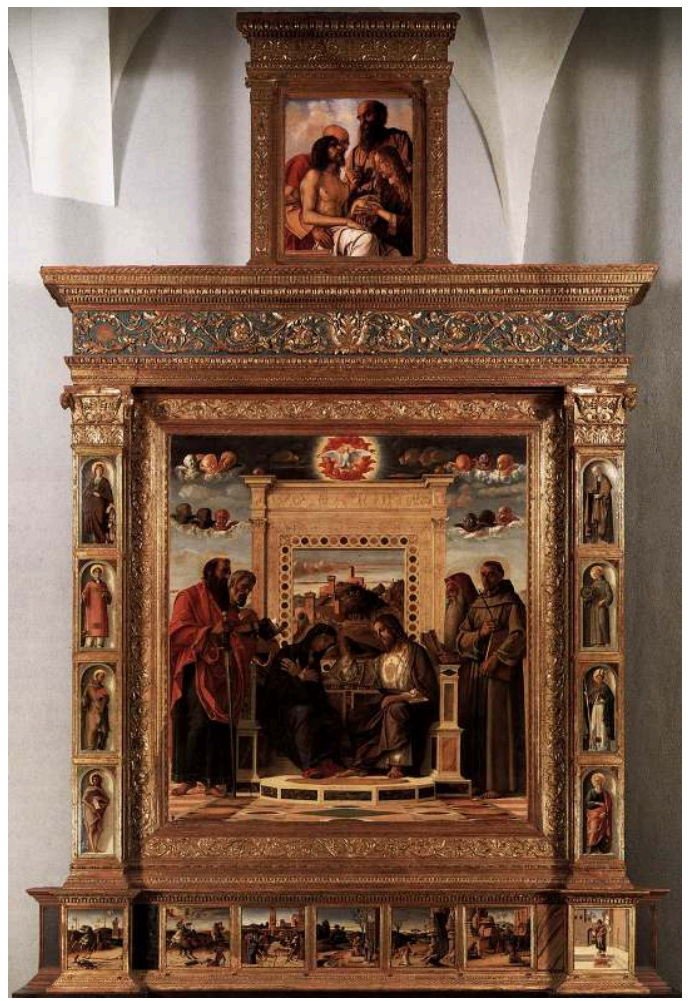

Giovanni Bellini, Couronnement de la Vierge, v. 1476, tempera et huile sur bois, $260 \times 235 \mathrm{~cm}$, Pesaro, Museo Civico ; Pietà (Onction), Pinacothèque du Vatican (voir suivant). Reconstitution du retable entier à l'occasion de l'exposition La Pala ricostruita, 1989 (voir n. 2)

Plus d'un quart de siècle plus tard, divers travaux ont permis de confirmer les suppositions de Wilson et de reconnaître dans cette image du Christ mort la cimaise de la Pala de Pesaro 3 . Pourtant, à ce jour, elle n'a toujours pas fait l'objet d'une analyse en profondeur. La présente étude propose de s'interroger sur la singularité de ce panneau, dans lequel Bellini se livre à des expériences tant iconographiques que matérielles. Nous nous pencherons sur ces deux aspects, les conjuguant, les examinant à la lumière de l'ensemble, pour mieux en révéler la complexité.

Tout d'abord, il est notable que Giovanni Bellini remanie le vocabulaire iconographique des thèmes de ces deux panneaux. Le Couronnement de la Vierge jouissait d'un succès certain depuis des générations dans la région, surtout chez les frères mineurs ${ }^{4}$. Ici, l'artiste associe le thème traditionnel à celui de la sacra conversazione, inventé depuis peu $^{5}$. De plus, il traite cette célébration de la Vierge devenant Reine des cieux de façon sensiblement grave, comme pour l'accorder à la scène de la Passion qui domine le tout ${ }^{6}$. Cette image aussi s'écarte des représentations habituelles. L'appellation Pietà peut convenir, si l'on prend ce terme dans son sens le plus large : une image du Christ mort, seul ou non, entre la Déposition et l'Ensevelissement, propre à inspirer la piété chez le spectateur dévot ${ }^{7}$. Certains ont pourtant bien vu que le thème de ce panneau présente un caractère bien plus inédit et spécifique dans la vaste iconographie de la Passion. Il 
s'agit d'un Embaument du Christ, une Onction, thème caduque que Bellini réinvente ici ${ }^{8}$.

Fig. 2

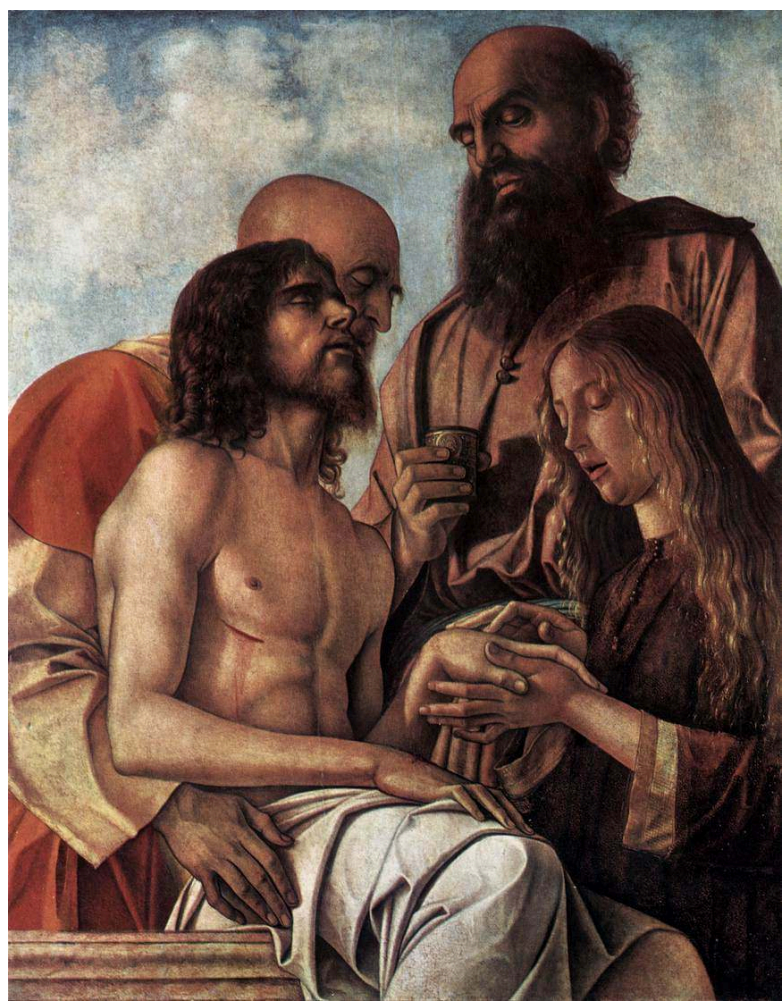

Giovanni Bellini, Pietà (Onction), v. 1476, tempera et huile sur bois, 107 x 84 cm, Pinacothèque du Vatican

Deuxième originalité majeure, l'artiste tranche par le choix du matériau. Son passage de la tempera à l'huile a beaucoup attisé les esprits. Une légende vasarienne, reprise par Sansovino, voulait qu'il eût dérobé la technique à Antonello da Messina qui séjourna à Venise en 1475-1476. Cette hypothèse est toutefois démentie par plusieurs faits?. Il est surtout notable que, depuis un certain temps déjà, avant la réalisation des panneaux de Pesaro, Bellini jouait de ce nouveau liant, l'ajoutant à des degrés variés au jaune d'œuf ou à la colle ${ }^{10}$. Sur les panneaux en question, on trouve encore ce mélange de médium. Mais il semble qu'ici, pour la première fois, Giovanni exploite les possibilités de ce nouveau medium pour ses qualités propres ${ }^{11}$. Par le biais de sa transparence, les couleurs gagnent en luminosité. Par sa malléabilité, ses figures gagnent en plasticité mœlleuse.

5 Le cœur de cet article visera à démontrer que le double travail du Vénitien quant à l'iconographie et au choix du matériel ne peut être le fruit d'un hasard. Les deux innovations sont au contraire intimement liées l'une à l'autre. L'huile qu'utilise Giovanni Bellini fait référence à l'huile qu'évoque l'image d'une onction. Mais on peut aller encore plus loin. Il n'est pas interdit de penser, qu'étant liées, ces deux inventions donnent lieu à une troisième qui serait le sens même de l'œuvre. Cette huile, en soulignant la surface brillante, prend valeur comme plan à part entière. L'œil doit traverser ce plan, donc passer par l'huile, pour accéder à cet épisode clef de l'histoire sainte qui s'y déroule, cette Onction que l'huile même fait matérialiser devant lui. En 
passant par l'huile, le spectateur dévot reçoit en quelque sorte une onction de regard ${ }^{12}$ dont l'officiant serait l'artiste.

6 Un tel tour de force n'est explicité ni par une clause de contrat, ni par une hypothétique missive de l'artiste à son commanditaire, puisqu'aucune trace écrite ne nous est parvenue. Notre démonstration doit donc s'appuyer sur des biais indirects, plus subtils, aux confluents de l'histoire de l'art et de celle de la spiritualité. Le patrimoine artistique de Venise et des Marches, leurs coutumes visuelles et les pratiques de leurs artistes nous serviront de point d'appui. Et puisque les œuvres ici étudiées ne peuvent se concevoir sans la pensée sacrale qui les a engendrées, il faudra également recourir à ce contexte spirituel fait de théologie sacramentelle et de pratiques dévotionnelles. Forts de ces explorations, nous finirons par un ensemble de comparaisons afin de verser des pièces que nous espérons conclusives au dossier.

\section{Le retable}

7 Le cadre impressionne par sa grandeur et son élaboration. En charpente massive revêtue d'or et de bleu, ce châssis a suscité de vifs débats quant à sa forme primitive, les changements successifs qu'il a pu subir, sa provenance, la main qui l'a créé et la source de son inspiration. La critique s'accorde, cependant, sur le fait que le cadre présente une telle harmonie, entre ses différents éléments et avec le sujet peint, qu'il a dû être conçu au moins en partie par Bellini lui-même en fonction de l'image figurée ${ }^{13}$. Tradition et innovation s'y côtoient. Les saints en miniature sur les marges, ceux de la prédelle, le contraste des ors et des bleus, viennent d'un vocabulaire artistique finissant. Les deux panneaux quadrangulaires superposés, en revanche, appartiennent pleinement à l'idiome moderne. Leurs encadrements respectifs se ressemblent par leur forme et par leur décoration à l'antique : pilastres, corniches, chapiteaux, arabesques.

Un cadre classicisant a déjà vu le jour dans la peinture de l'Italie du nord chez Andrea Mantegna avec, par exemple, le Triptyque de San Zeno à Vérone dans les années 1456-1459 (fig. 3) ${ }^{14}$. 
Fig. 3

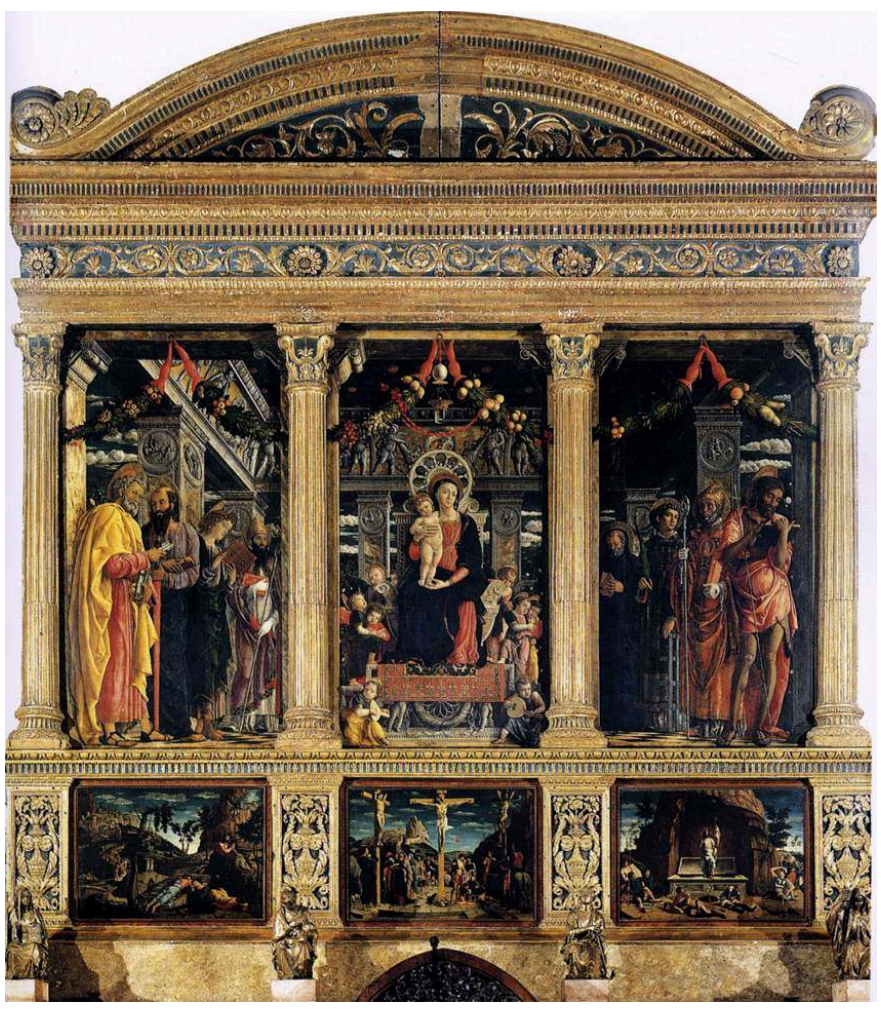

Andrea Mantegna, Triptyque de San Zeno, 1457-1460, tempera sur bois, $212 \mathrm{~cm} \times 460 \mathrm{~cm}$, Verona, San Zeno

9 Un peu plus tard, un autre exemple provient de ce même milieu padouan, de la main de Marco Zoppo, avec la Pala de San Giovanni Battista (fig. 4), elle aussi destinée à Pesaro. Quant à l'œuvre de Mantegna, une stricte parenté avec le cadre de Bellini est contredite par des formes qui sont, au demeurant, assez différentes. Ce qui lie les deux œuvres bien plus étroitement tient dans l'usage qui en est fait : la reprise du cadre sculpté à l'intérieur de l'espace fictif du tableau. 
Fig. 4

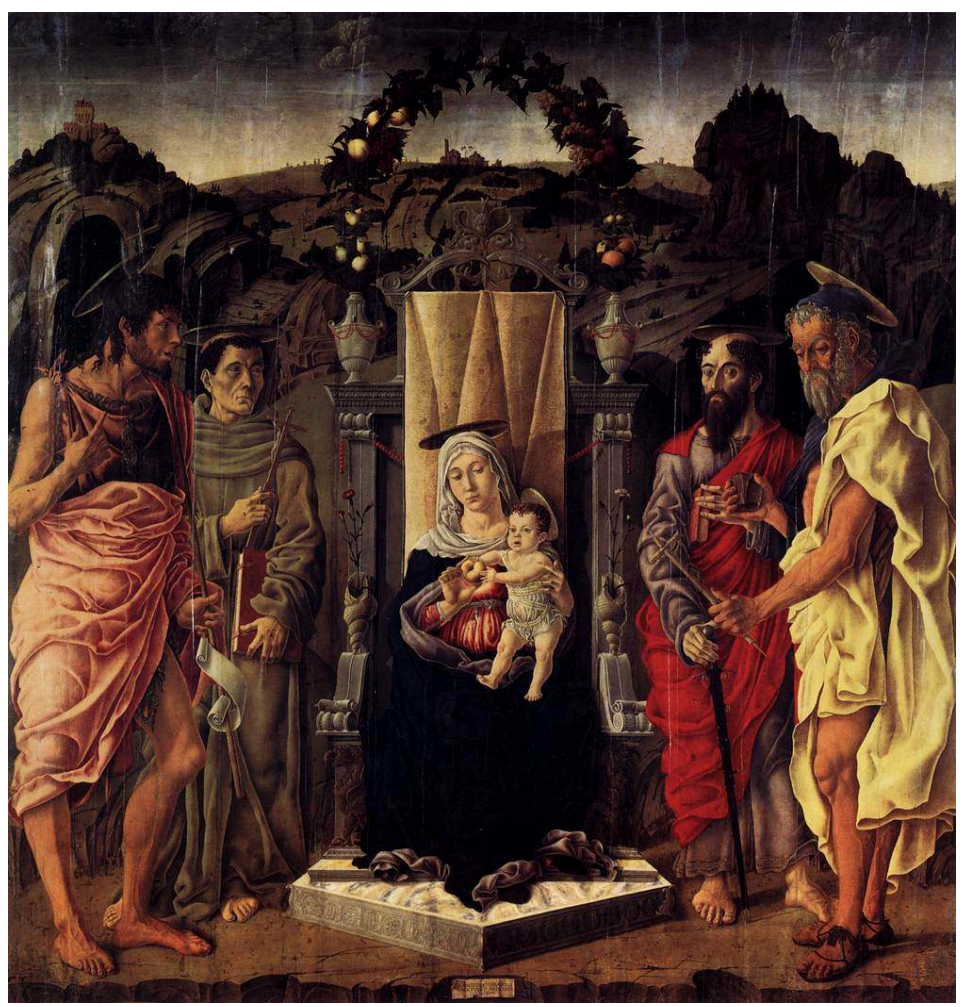

Marco Zoppo, Pala de San Giovanni Battista, tempera sur bois, 120 × 95 cm, Berlin, Staatliche Museen

10 Cependant, les deux artistes se séparent l'un de l'autre quant à l'effet voulu. Dans le triptyque, le cadre réel semble se continuer en une frise autour de la chambre où trône la Vierge, créant une impression de chambre ouverte. Le cadre devient une sorte de porte ouvrant sur l'espace sacré. Dans le retable de Pesaro, l'effet relève plutôt d'une succession de plans. Celle-ci est mise en œuvre dans un premier temps par l'emboîtement de cadres successifs pour chaque panneau, où chaque cadre principal est suivi d'une marie-louise. Cet effet est prolongé par la répétition de la forme des cadres supérieurs et inférieurs entre eux, puis par la reprise du cadre dans l'espace fictif, cette fois sous la forme du dossier de trône où siègent le Christ et sa Mère. Entre le dossier peint et le cadre sculpté, la décoration révèle des variations plus ou moins sensibles. Toutefois, l'un renvoie spécifiquement à l'autre : de pilastre en pilastre, les mesures du cadre de l'Onction coïncident exactement avec celles du dossier du trône ${ }^{15}$. L'œuvre de Vérone relève du trompe-l'œil, celle de Pesaro d'une mise en abîme régissant la lecture du tableau ${ }^{16}$.

11 Dans l'espace sacré de la peinture, la forme de ces différents cadres réapparaît donc comme le dossier du trône où le Christ couronne sa Mère. Les sculptures et la marqueterie sont d'un extrême raffinement. Les panneaux de marbre qui l'entourent servent à relier le trône au pavement dont il est légèrement surélevé. Autour du couple divin méditent les saints: Paul, Pierre, Jérôme et François. Derrière, on devine des sommets de montagnes contre un ciel diurne où volètent des angelots. Au milieu, entourée de séraphins, la colombe du Saint Esprit semble vouloir se poser sur le haut du trône. Une ouverture dans le dossier laisse apparaître un autre paysage, dominé par une forteresse sur une montagne, sans accord d'échelle avec celui placé derrière la scène principale. Un certain positivisme a voulu à tout prix identifier cette forteresse 
avec une structure réelle, la Rocca Gradara ou la Rocca Costanza. Je n'entre pas dans ce débat qui me semble passer à côté de l'essentiel ${ }^{17}$. Bellini - quoi qu'il en soit d'une forteresse concrètement située dans les parages - a sûrement voulu par dessus tout figurer la Jérusalem céleste, Maria-Ecclesia et par là, le corps mystique du Christ ${ }^{18}$. De ce couple et de la scène qui les entoure, se dégage une impression de paix teintée de gravité qui s'harmonise avec la scène qui se déroule dans la cimaise ${ }^{19}$.

Cette image est d'apparence très simple. Au bord du sarcophage, seul point de repère spatial, le corps du Christ est soutenu par Joseph d'Arimathie. Marie-Madeleine est occupée à oindre sa main tandis que Nicodème se tient en arrière et au-dessus de tous, tenant le vase où la Madeleine puise les onguents. Le corps du Christ est ainsi offert au spectateur. Comme pour d'autres Pietà de Giovanni Bellini, le thème est sacramental, eucharistique. Dieu incarné est présenté au terme de son sacrifice à la contemplation du dévot ${ }^{20}$. Cette scène, à l'instar du Couronnement, se détache d'un fond naturaliste, mais sans la moindre trace de paysage. Comme il convient à une cimaise, on ne perçoit que la clarté d'un ciel bleu et quelques nuages. Le point de vue est assez bas, mais paradoxalement proche. La jambe du Christ, se projetant dans notre espace, brouille également les pistes ${ }^{21}$. Nous hésitons à convenir que le Christ soit posé vers l'extérieur du sarcophage, alors que Joseph, à l'intérieur, semble le tenir. La position est peu vraisemblable pour y coucher la dépouille. Il est encore plus difficile de situer Nicodème et la Madeleine. Celle-ci sert de base à une composition qui a été appelée pyramidale, mais qui interdit toute impression de base solide. Pourtant, la cohérence de la scène est garantie par des éléments plus subtils que le cadrage ou la perspective mathématique. D'aucuns ont souligné que les jeux d'ombre et de lumière dirigent le spectateur vers la "chorégraphie » des mains, la sainte qui oint le Christ ${ }^{22}$. Poussons plus loin l'analyse. Le sens de la composition tient à la force centripète des regards. Marie-Madeleine est toute entière à sa tâche. Il n'est pas toujours aisé de distinguer l'objet qui attire l'attention des deux hommes. Fixent-ils le baume ou la plaie embaumée ? Cette ambiguïté n'en est finalement pas une : vase et plaie sont corollaires. Ce qui est puisé dans l'un est donné à l'autre, certes. Mais leur gémellité est aussi structurale en ceci que tous deux sont des creux qui déversent des liquides. La plaie ointe n'est pas visible sous cet angle; à sa place, la plaie du côté s'offre au spectateur comme pour condenser en elle seule toutes les blessures reçues à la Passion. En outre, ces trois points, c'est-à-dire la plaie qui s'écoule, celle qui est ointe, et le vase, forment ensemble une triade à l'intérieur des personnages, soulignant l'effet pyramidal. Cette triade constitue dans le tableau ce qu'il serait mieux convenu d'appeler le cœur que le centre. Quel que soit le point spécifique, tout regard y est rivé, dans l'acte de l'onction.

L'iconographie, que l'on voit inséparable de la composition, est tout aussi surprenante. Dans les formules les plus classiques du Christ Mort entouré, la présence de MarieMadeleine, et à plus forte raison celle de Nicodème et de Joseph, dépendent de celle de la Vierge Marie et de Jean l'Évangéliste. Ici, ces derniers sont absents et les acteurs secondaires passent au premier plan. De même, le vase d'onguent mérite un regard attentif. Avec sa dorure ouvragée et ses possibles effets de rosechiero, il pourrait être un chef-d'œuvre du meilleur fiolario de Murano, et même au-delà ${ }^{23}$. Il n'y a pas, à ma connaissance, de vase de parfum, dans l'iconographie de la Passion qui puisse s'y comparer ${ }^{24}$.

14 Cette particularité ne se limite pas à sa seule forme. Bellini exploite le vase à d'autres fins encore. En le plaçant dans les mains de Nicodème, l'artiste renoue avec les scènes 
d'onction françaises du treizième siècle, qui montrent le saint homme dans l'acte de verser les baumes sur le corps du Christ. On trouve parfois le vase dans les mains de ce personnage dans l'art italien du Trecento et Quattrocento ${ }^{25}$. De telles scènes rappellent le passage biblique racontant qu'il aurait apporté de la myrrhe et de l'aloès pour l'embaumement. Toutefois, Bellini joue de ses choix iconographiques. Pour l'Italie de ce troisième quart du Quattrocento, cet objet est plus habituellement l'apanage de Marie Madeleine, qui ici ne le tient pas, mais y puise pour appliquer le baume sur les plaies. Pourtant, le vase dans ses mains est son signe identificateur. L'idée de l'onction est même si essentielle au personnage qu'elle a servi à le construire, comme nous le verrons plus loin. Et cependant, malgré les nombreux récits selon lesquels la Madeleine aurait oint le Christ, jamais elle ne l'aurait embaumé. Ainsi Bellini joue avec ce vase un tour de passe-passe qui brouille les pistes de la tradition iconographique. Les liens, habituellement ténus, entre Nicodème et la Madeleine s'en trouvent ainsi resserrés. Plus encore, c'est également grâce au vase - à sa présence prononcée au cœur du tableau - que la Pietà traditionnelle s'est infléchie, que Bellini donne à voir une Onction.

Le pauvre état des archives de San Francesco empêche de trouver une indication écrite concernant l'emplacement d'origine de l'ensemble. Selon toute probabilité, l'œuvre de Giovanni Bellini devait tenir la place d'honneur au-dessus du maitre-autel ${ }^{26}$. Des multiples indices qui le suggèrent, nous en retiendrons ici quelques-uns. Sa thématique écclesiale-eucharistique correspond au centre liturgique de l'église. De même, il était coutumier chez les franciscains du Quattrocento de placer les représentations des grands thèmes mariaux dans l'axe central, sur l'autel principal ${ }^{27}$. De cette façon également, pour la pala en question, l'arc triomphal du sanctuaire, et le jubé qui y mène, réitèrent le dispositif de l'encadrement.

Quelles circonstances ont pu donner le jour à ce retable? Si nous ne connaissons pas son commanditaire, nous pouvons, dans une certaine mesure, retrouver le contexte qui l'a vu apparaître.

\section{Contexte et environnement}

\section{Pesaro et la commande}

Pesaro, nous l'avons dit, quoique situé dans la province des Marches, se trouve bien dans l'orbite des échanges commerciaux et artistiques avec la Sérénissime. Gentile da Fabriano, Iacobello del Fiore, Pisanello et Carlo Crivelli sont les témoins de la richesse de ces contacts et forment ce qu'on pourrait appeler l'école vénéto-marchésane. Comme Venise, Pesaro est une ville portuaire qui regarde vers l'Orient. Quand les Turcs prennent Constantinople en 1453, c'est à Pesaro que se réfugieront les Paléologue et les Comnène ${ }^{28}$. Si, après cette date fatidique, l'Orient devient plus facile à rêver qu'à visiter, les communications persistent ${ }^{29}$.

Pendant près de deux siècles, Pesaro vit sous le règne des Malatesta, jusqu'en 1445, quand les Sforza prennent le pouvoir. Les deux dynasties se montrent grands mécènes de la ville et surtout de ses structures franciscaines. Si par la suite les Sforza préfèrent l'église observante de San Giovanni Battista, les premiers s'intéressent à San Francesco au point de vouloir en faire leur nécropole. C'est avec le concours des grands seigneurs que l'église, consacrée dès 1359 , se verra gratifiée d'un portail sculpté en pierre blanche 
et marbre rose. La matière première est précieuse, travaillée de façon à rappeler les créations architecturales de Venise. Ce sera également à Venise que l'on ira chercher, vers 1410 , un artiste à même de créer un retable digne de la sainte ${ }^{30}$ - Michelina da Pesaro - dont les reliques honorent l'église. On le trouvera justement dans le milieu de Jacopo Bellini, en la personne de Iacobello del Fiore. Dans son polyptyque (fig. 5), Michelina, figure principale, surgit du fond en haut relief de bois polychromé, tandis que les saints latéraux sont simplement peints entre des colonnes sculptées.

Fig. 5

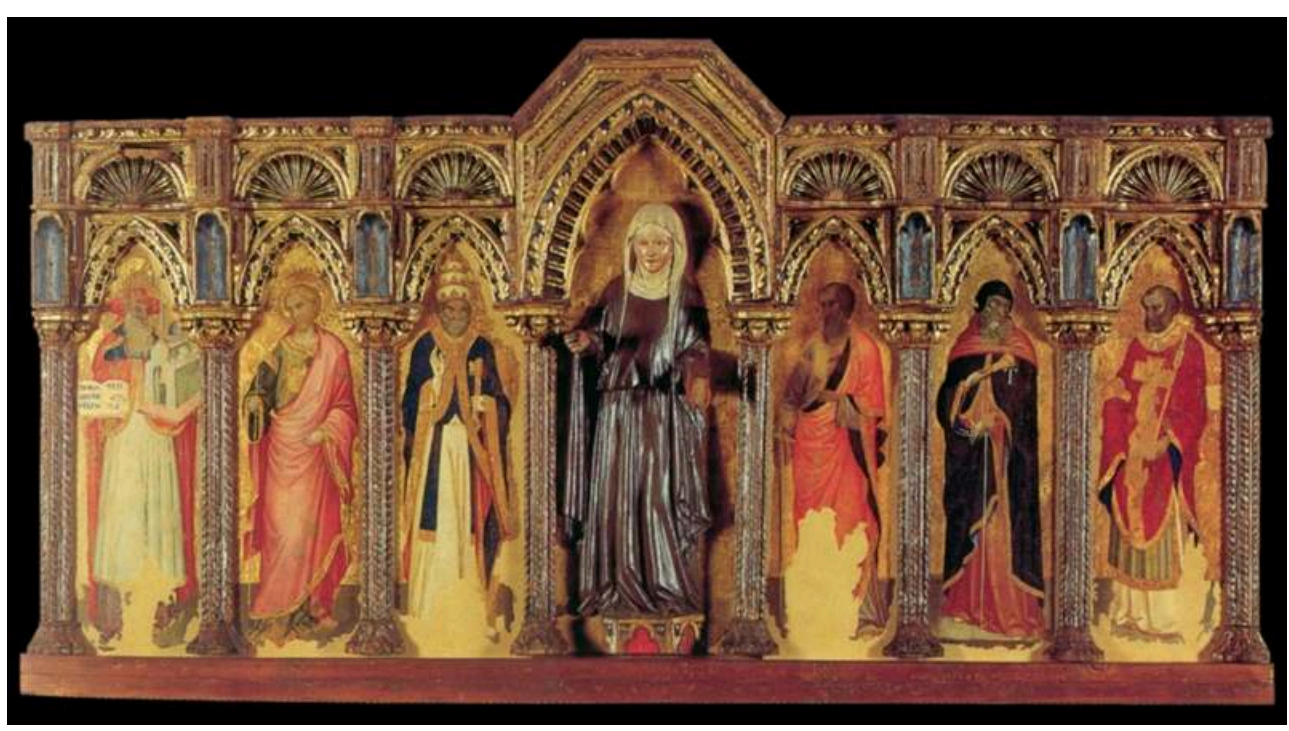

Jacobello del Fiore, Polyptyque de la Beata Michelina da Pesaro, v. 1410, tempera sur bois, $129 \times 245$ $\mathrm{cm}$, Pesaro, Museo Civico

19 Au cours du quinzième siècle, San Francesco sera dotée de trois nefs. À la suite de ces remaniements, le polyptyque de Iacobello se trouvera dans la chapelle de Michelina, à la tête de la nef droite ${ }^{31}$.

La bienheureuse vécut dans la première moitié du Trecento, s'inscrivant dans le mouvement de mystiques pénitentes qui florissait alors en Italie dans l'entourage des ordres mendiants. Sous l'impulsion des Malatesta - qui se flattaient de l'avoir dans leur parenté $^{32}$ - et grâce aux bons soins des frères mineurs, Michelina trouva sa place dans le panthéon marchesan des saints thaumaturges. Les fidèles venaient de loin pour chercher remède à toutes sortes d'afflictions. Dans le troisième quart du quinzième siècle, elle se montrait toujours efficace, guérissant d'une fièvre le frère mineur Frederico da Lucignona. En remerciement, ce dernier écrivit pour la sainte une Vita rimée en 1476, dans les années où Bellini composait son retable ${ }^{33}$.

Quelques années auparavant, en 1471, comme nous l'avons signalé plus haut, les franciscains de l'Observance installés à San Giovanni Battista avaient passé une commande pour un retable auprès de Marco Zoppo, à Padoue ${ }^{34}$ (fig. 4). Entre une prédelle historiée et une cimaise qui figure un Christ mort, le panneau central est une corniche rectiligne qui montre une Sacra Conversazione sur fond de paysage. Les similarités avec le panneau de Bellini (fig. 1) vont jusque dans le choix des saints représentés, à l'exception de Jean-Baptiste, patron de l'église, qui est remplacé à San Francesco par Pierre ${ }^{35}$. Il se peut qu'un Sforza soit à l'origine de l'œuvre de Zoppo. Alessandro, par exemple, a été suggéré comme possible commanditaire pour sa fille 
Battista, dans cette église vouée à son saint onomastique et qui sert également de nécropole à la dynastie ${ }^{36}$.

Un tel cas de figures est moins probable pour la pala de Bellini. Lieu fort des Malatesta, l'église conventuelle ne jouissait pas de la même faveur auprès des Sforza. Du reste, comme le remarque justement Goffen, aucun saint de la famille dominante n'apparait dans la pala de San Francesco. Si l'on ne peut éliminer toute possibilité d'une commande des Sforza, il serait plus sûr et plus fructueux d'explorer les pistes de la pensée franciscaine pour comprendre le programme bellinien. Les similarités entre les deux pale de Pesaro nous encouragent dans cette direction ${ }^{37}$, d'autant plus judicieuse que Bellini s'est montré, tout au long de sa carrière, un éloquent interprète de la spiritualité des frères mineurs ${ }^{38}$.

\section{Culture visuelle : l'insoutenable légèreté d'être lagunaire}

Étant donné l'histoire de l'église et de sa ville, le choix d'un Vénitien en vue pour une parure de plus n'avait pas de quoi surprendre. Pourtant, la carrière d'un Piero della Francesca, à Rimini, à Urbino, à Pesaro même, donne à croire que l'école toscane était également appréciée. La capacité de ses peintres à faire oublier la peinture, à faire abstraction de l'existence matérielle de l'image était, pourtant, aux antipodes du goût autochtone. Celui-ci affirmait volontiers la substance et le support d'une image, pour des raisons qui trouvent leurs sources dans la spécificité culturelle de la Sérénissime.

Dans cette ville-sœur de Constantinople, la chute de la capitale orientale ne fait qu'attiser le sens d'appartenance à la culture byzantine. La tradition de l'icône était toujours vive. C'est de cette période que date leur importation en masse par des artistes crétois, s'efforçant de répondre à la demande vénitienne ${ }^{39}$. Porteuses de grâce divine, au même titre que les reliques, les icônes tissaient un lien entre l'au-delà et l'ici-bas ${ }^{40}$. Parmi les plus importantes de ces icônes était l'Imago Pietatis, image du Christ mort en buste, dépourvu de tout élément narratif, ancêtre de la Pietà. La version la plus connue en était une petite mosaïque à Santa Croce in Gerusalemme à Rome. Ses gardiens voulaient qu'elle fût un original, reproduit d'après une vision qu'aurait eue Grégoire le Grand au cours d'une messe, au moment même de la transsubstantiation. Forte de ce double aspect sacramental et miraculeux, l'image serait la reproduction fidèle, le portrait même du Christ de la Passion, au même titre que le voile de Véronique, envoyé par la volonté de Dieu. En réalité, la légende, postérieure à la mosaïque, elle-même tardive, bute contre les faits. Le motif, qui provient certainement de celui d'une icône orientale, a rencontré un vif succès, particulièrement à Venise, d'où proviennent les premiers et les plus nombreux exemples. L'histoire pieuse qui s'y est attachée par la suite n'a fait qu'accroître le prestige dont il jouissait déjà ${ }^{41}$.

L'Imago Pietatis recoupe un autre type d'image miraculeuse que Venise héritait de Byzance : ces Madones, Christ et autre saints qui, comme un être de chair, parlent, pleurent, suintent, allaitent, saignent. La basilique de San Marco recelait même du sang répandu par le crucifix de Beyrouth au moment où un juif l'aurait frappé (dont on verra plus loin l'importance pour notre propos). Ce sang, mêlé à de l'eau, en aspergeant tous les juifs qui regardaient, aurait provoqué leur conversion. Remontant, selon la légende, aux origines du christianisme, ce crucifix servait de modèle à une série d'autres crucifix véhiculant des histoires similaires ${ }^{42}$. À San Marco aussi il s'en trouvait un qui portait toujours des «cicatrices $»^{43}$. De telles images se rattachaient en général à une 
provenance byzantine, présentant des qualités comparables à celles des icônes, voire celles des reliques. Elles partageaient toutes un même pouvoir de conjonction, par une efficacité matérielle à capter la puissance essentielle de leur source en la diffusant sur terre.

Souvent somptueusement décorées, les icônes sont aussi représentatives d'autres aspects artistiques dont la ville se vante et qui relèvent de sa proche parenté avec le Levant : le travail du marbre, de la mosaïque, le verre de Murano, la variété et la qualité des pigments qui viennent sur le Rialto dans les mêmes cargaisons que des pierres précieuses et des étoffes luxueuses. Jouissant d'une source si riche en matières nobles, les artistes de la lagune, loin de les transcender, font valoir le sens dont ces matériaux peuvent être porteurs.

Quand, vers 1423, Gentile da Fabriano se met à l'œuvre pour créer son Adoration des Mages (fig. 6) à Florence, il ne le peint pas seulement. Il le poinçonne, il l'incruste, il le damasquine, il le sculpte, il le façonne. Le résultat ressemble autant à un chef d'œuvre d'orfèvrerie qu'à un tableau d'autel, comme pour démontrer aux sobres Florentins la force de la tradition vénitienne dans toute sa gloire.

Fig. 6

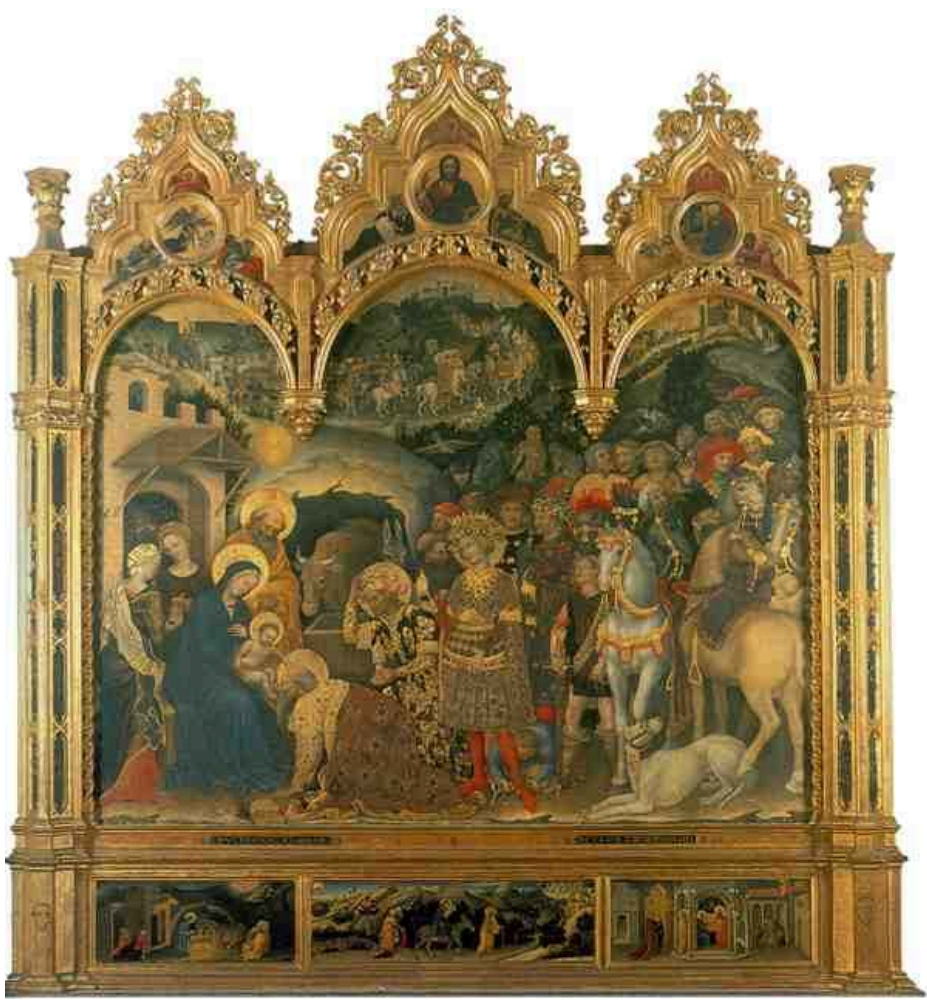

Gentile da Fabriano, Adoration des Mages, tempera sur bois, sculpture en bois doré, 1423, 300 × 282 $\mathrm{cm}$, Florence, Galerie des Offices

Vers 1405, il opère dans le même registre sur le Retable de Valleromita pour les franciscains de sa ville natale. Sa figure de Marie-Madeleine en pied est peint sur le fond d'or (fig. 7). Elle porte le vase qui l'identifie à la main, en forme de pyxide. Aucun pigment n'est employé pour le matérialiser. Ciselé à même le fond d'or, il effleure les mains de la sainte. À peine perceptible, ce vase sacré fait partie intégrante du seul métal qui convient, selon les commentateurs, aux patènes et calices. 
Fig. 7

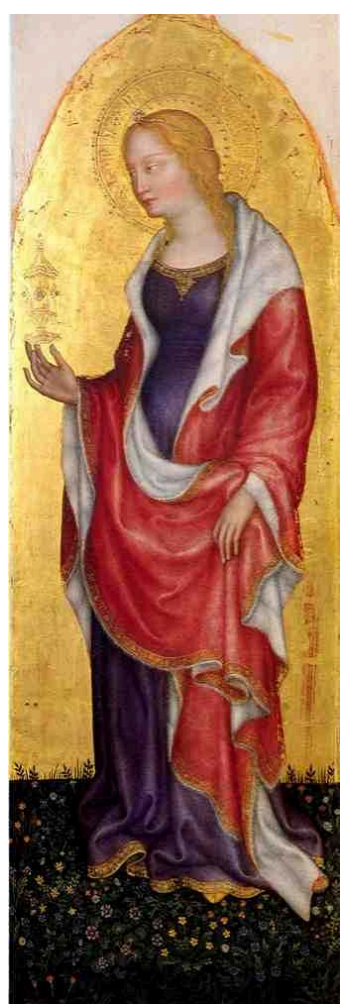

Gentile da Fabriano, Retable de Valleromita, détail : Marie-Madeleine, v. 1405-1410, tempera sur bois, $117 \times 40 \mathrm{~cm}$, Milan, Pinacothèque de Brera

L'invention a frappé les esprits, surtout en mouvance vénitienne et franciscaine. Michele di Matteo, par exemple, l'imitera en figurant la même sainte dans une œuvre datée après $1429^{44}$. Carlo Crivelli aussi s'en souviendra pour le Polyptyque de Montefiore, vers $1473^{45}$ (fig. 8). Dans chacune de ces œuvres, ces artistes, tout en affirmant la matière, la dématérialisent, la subliment. 
Fig. 8

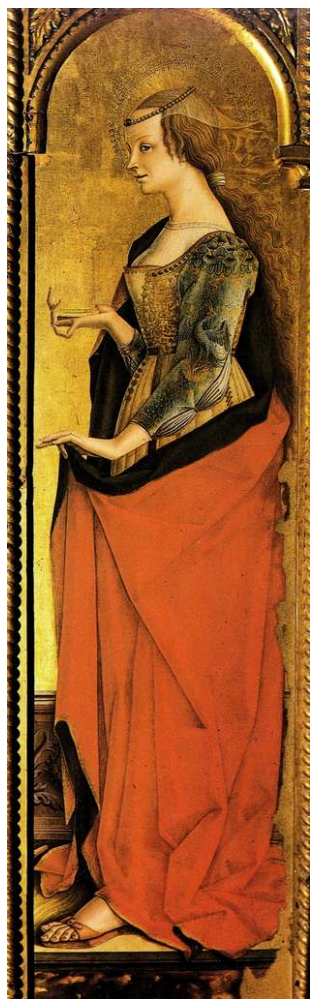

Carlo Crivelli, Polyptyque de Montefiore, détail : Marie-Madeleine, v. 1471-1473, tempera sur bois, 174 x $54 \mathrm{~cm}$, Montefiore dell'Aso, San Francesco

Replacé dans une telle perspective, le Polyptyque de Michelina (fig. 5), cité plus haut, relève lui aussi d'une confusion des processus optiques dans un but dévotionnel. Vers 1410 , comme nous l'avons vu, Iacobello mélange peinture et sculpture, ouvre les deux dimensions du panneau vers une troisième, pour que surgisse la sainte titulaire de la chapelle dans l'espace du dévot qui vient la prier. On ne retrouve des techniques semblables qu'avec Antonio Vivarini vers 1464, dans le Polyptyque de Saint Antoine Abbét6 (fig. 9) pour la confrérie éponyme de Pesaro, après les avoir expérimentées vers 1443 sur le Polyptyque de la Vierge dans l'église San Zaccaria à Venise ${ }^{47}$. De tels procédés tirent parti du matérialisme de la culture visuelle pour renvoyer à la fonction iconique : jouer un rôle de médiateur entre le céleste et le terrestre. 
Fig. 9

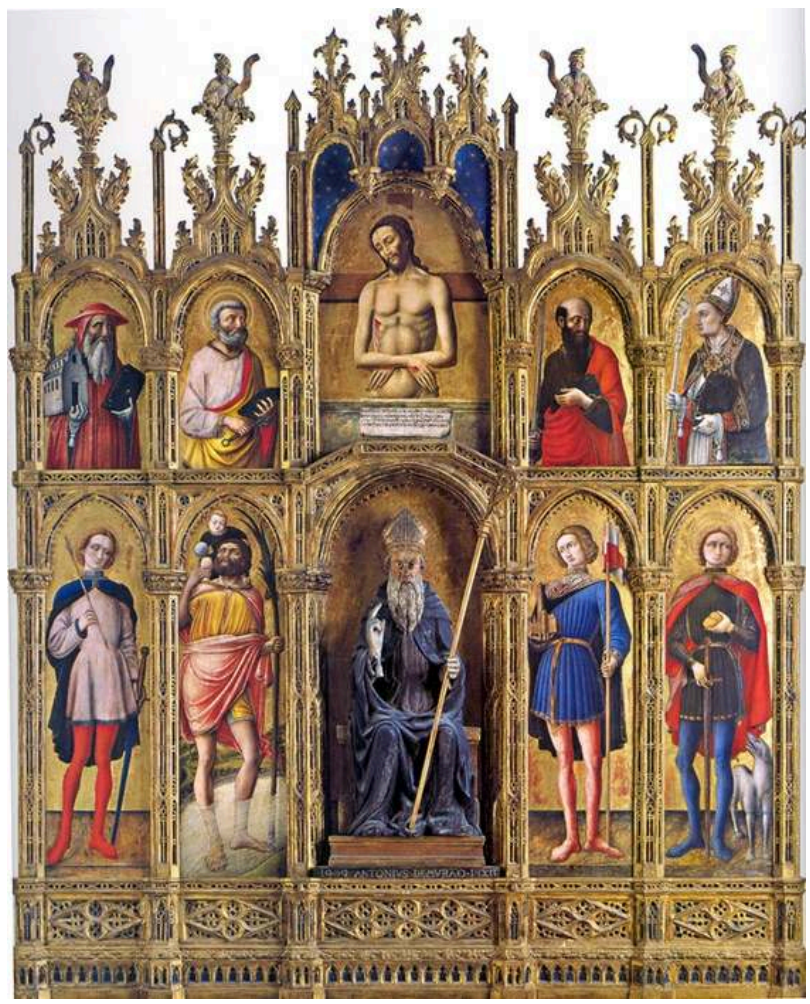

Antonio Vivarini, Polyptyque de Saint Antoine Abbé, 1464, tempera sur bois et sculpture peinte en bois, Pinacothèque du Vatican

31 Le goût pour le trompe-l'œil, si caractéristique de cette école, évolue dans la même pensée, comme le montre bien l'œuvre de Carlo Crivelli. Sa Madeleine ${ }^{48}$ (fig. 10), peinte vers 1475 , peut servir d'exemple. Les tresses de la sainte semblent se détacher de la surface du panneau et son pied paraît sur le point de quitter les arcatures qui la contiennent. La perception de ces éléments est d'autant plus perturbée que certains détails, par l'usage de pastaglie a relievo, telles la bordure du bustier, la boucle de la ceinture, l'auréole, la barrette, surgissent effectivement de la surface plane du tableau. L'œil doit parfois renoncer à distinguer entre les mondes situés de part et d'autre de la surface. 
Fig. 10

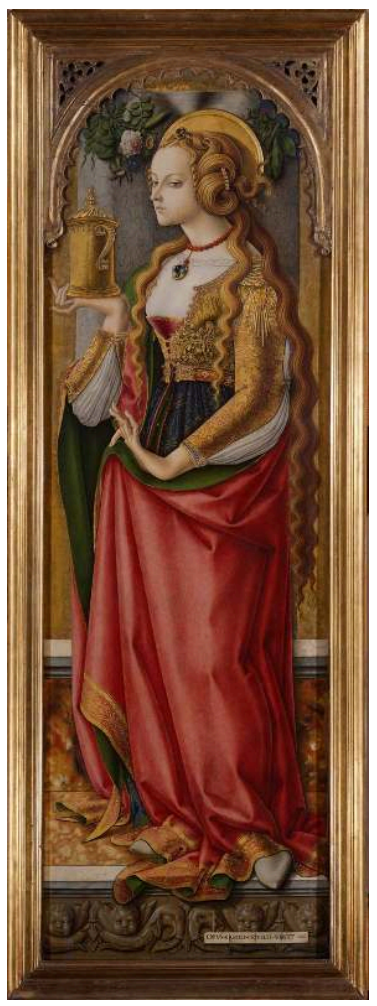

Carlo Crivelli, Marie-Madeleine, v. 1480-90, tempera sur bois, 152 × 49 cm, Amsterdam, Rijksmuseum

32 Or, par affirmation ou par négation de la surface, le principe qui régit ces divers artifices demeure le même. En jouant sur l'haptique, le textural, l'artiste parvient à confondre les plans et ainsi à suggérer au regard la possibilité de transiter entre l'espace profane et l'espace sacré.

En tout cela, Giovanni Bellini se montre digne fils de la Sérénissime. Ses surenchères sur le cadre-porte de Mantegna (fig. 3) ne se limitent pas au seul retable de Pesaro.À partir des années 1470, nombre de ses grandes Sacre Conversazioni pour les ordres mendiants montrent une suite d'expériences sur l'encadrement comme moyen de joindre deux mondes contigus. Celles des Frari (fig. 11), de San Giobbe (fig. 12), de Sainte Catherine de Sienne (perdue : gravure fig. 13) et de San Zaccharia (fig. 14), montrent toutes une architecture fictive qui renvoie à l'architecture du cadre. 
Fig. 11

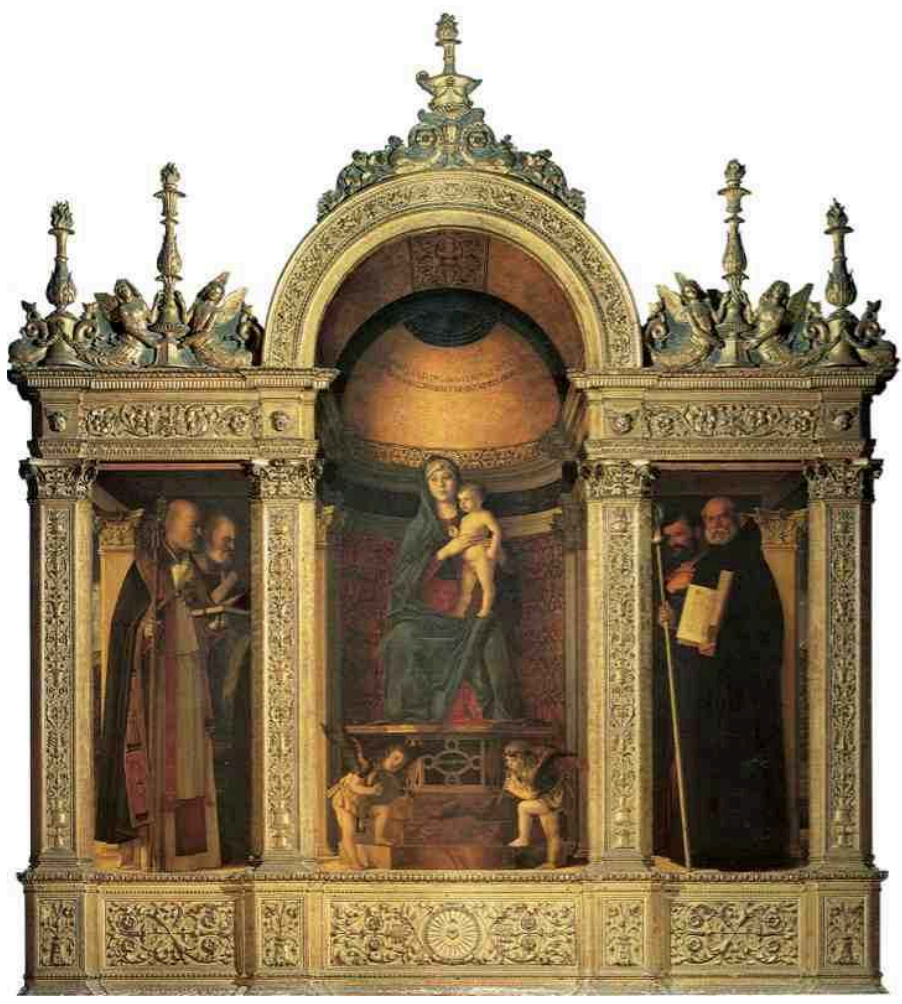

Giovanni Bellini, Triptyque des Frari, 1488, huile sur bois, 184 × 79 cm, Venise, Santa Maria Gloriosa dei Frari 
Fig. 12

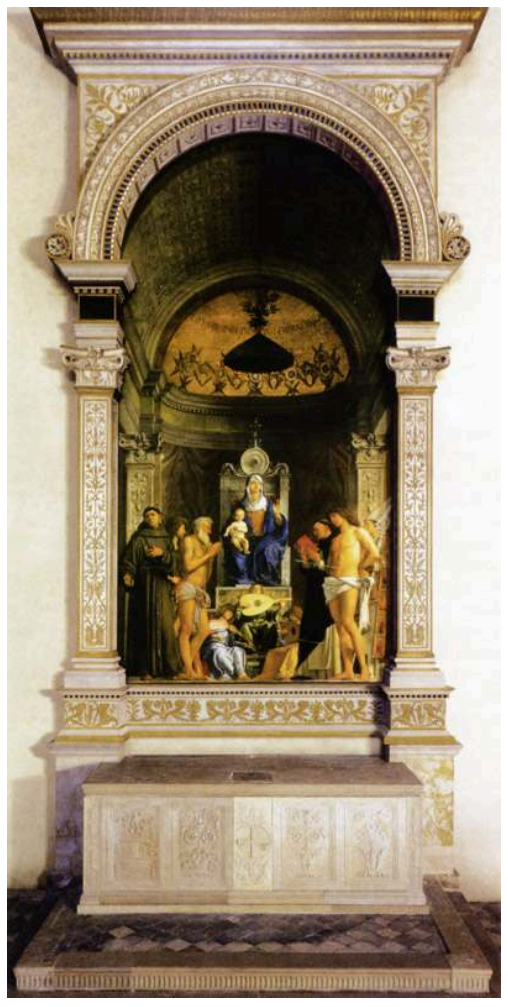

Giovanni Bellini, Pala de San Giobbe dans son cadre d'origine, reconstitution photographique Felix Thürlemann, 1487, huile sur bois, 471 × 258 cm, Venise, Galerie de l'Académie

Le retable dédié à Sainte Catherine, nous intéresse particulièrement ici, car la réflexion est poussée plus loin encore, et sera reprise vers la fin de la vie de Bellini dans le Retable de San Zaccaria. 
Fig. $13 \mathrm{a}$

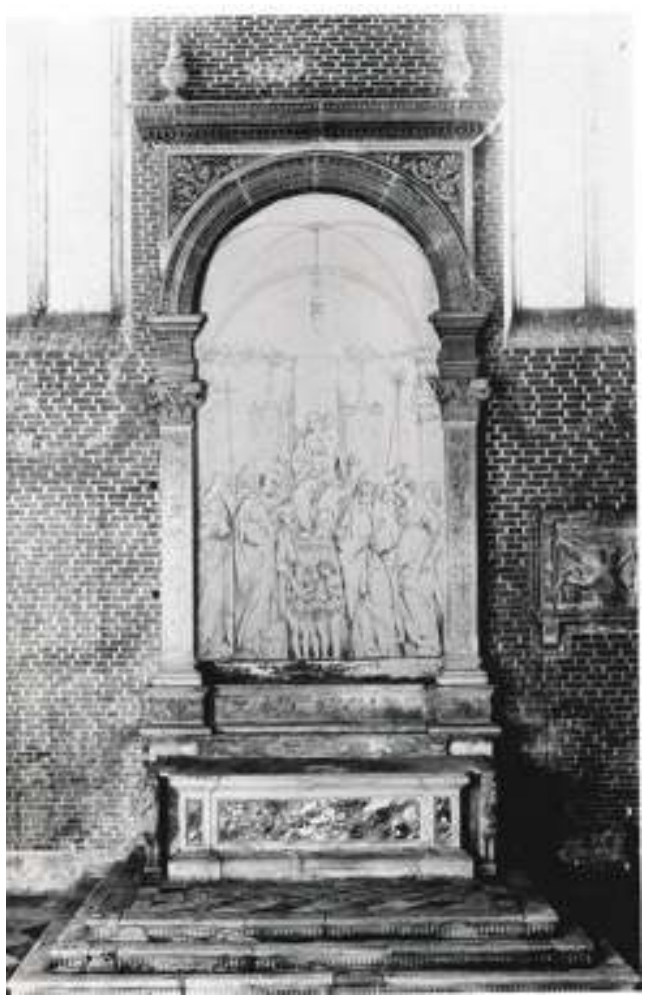

D'après Giovanni Bellini, gravure de la Pala de Sainte Catherine de Sienne, Originellement à San Zanipolo, reconstitution photographique tirée de Peter Humfrey (note 5), fig. 50 et fig. 51, pp. 68-69

Fig. 13b

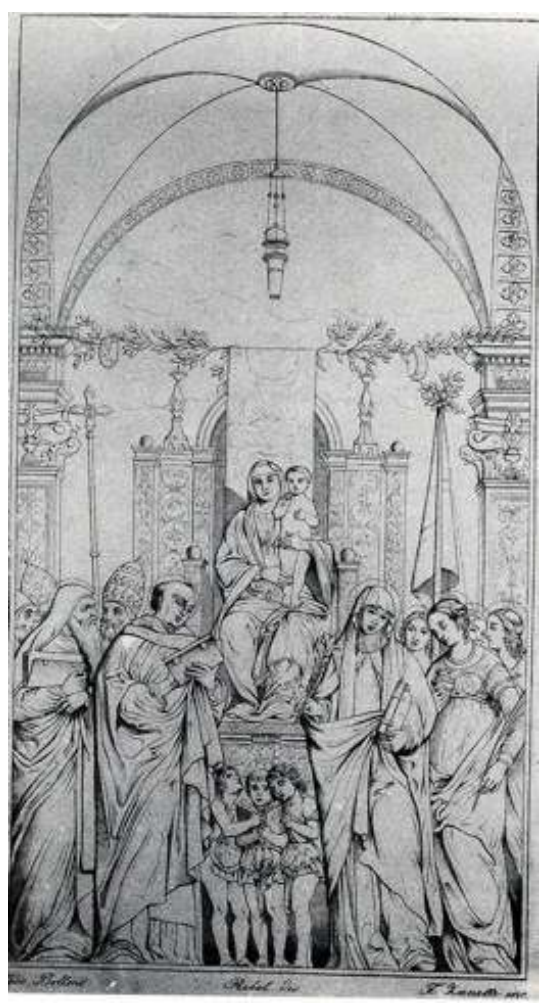

D'après Giovanni Bellini, gravure de la Pala de Sainte Catherine de Sienne 
Fig. 14

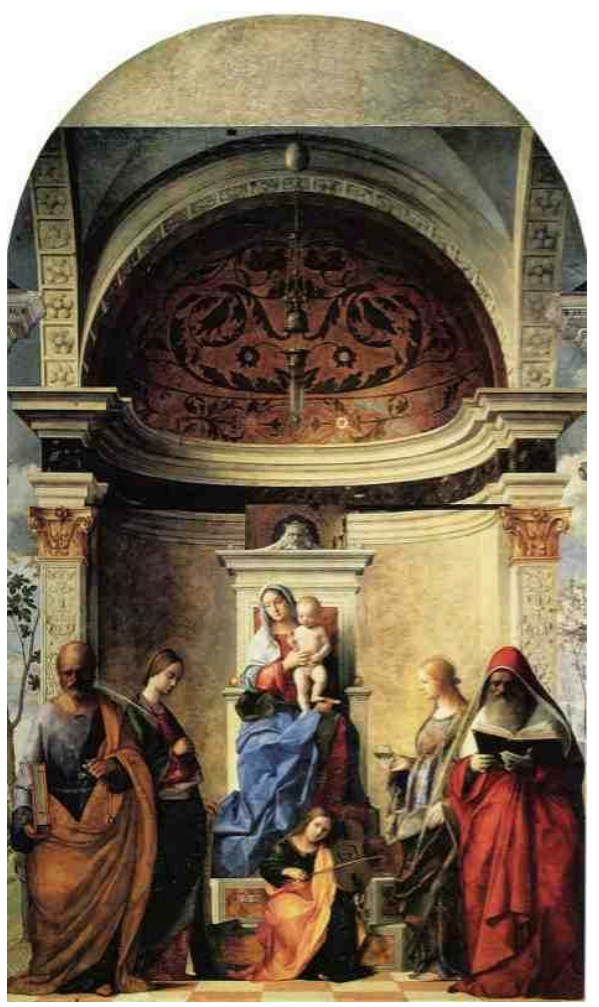

Giovanni Bellini, Pala de San Zaccaria, 1505, huile sur bois, 500 × 235, Venise, San Zaccaria

Cette pala, connue aujourd'hui seulement par le biais de reproductions, doit avoir été peinte à une date très proche de l'œuvre de Pesaro et montre à l'égard de la composition un rapport étroit avec la Pala de San Cassiano d'Antonello da Messina (fig $15)$. 
Fig. 15

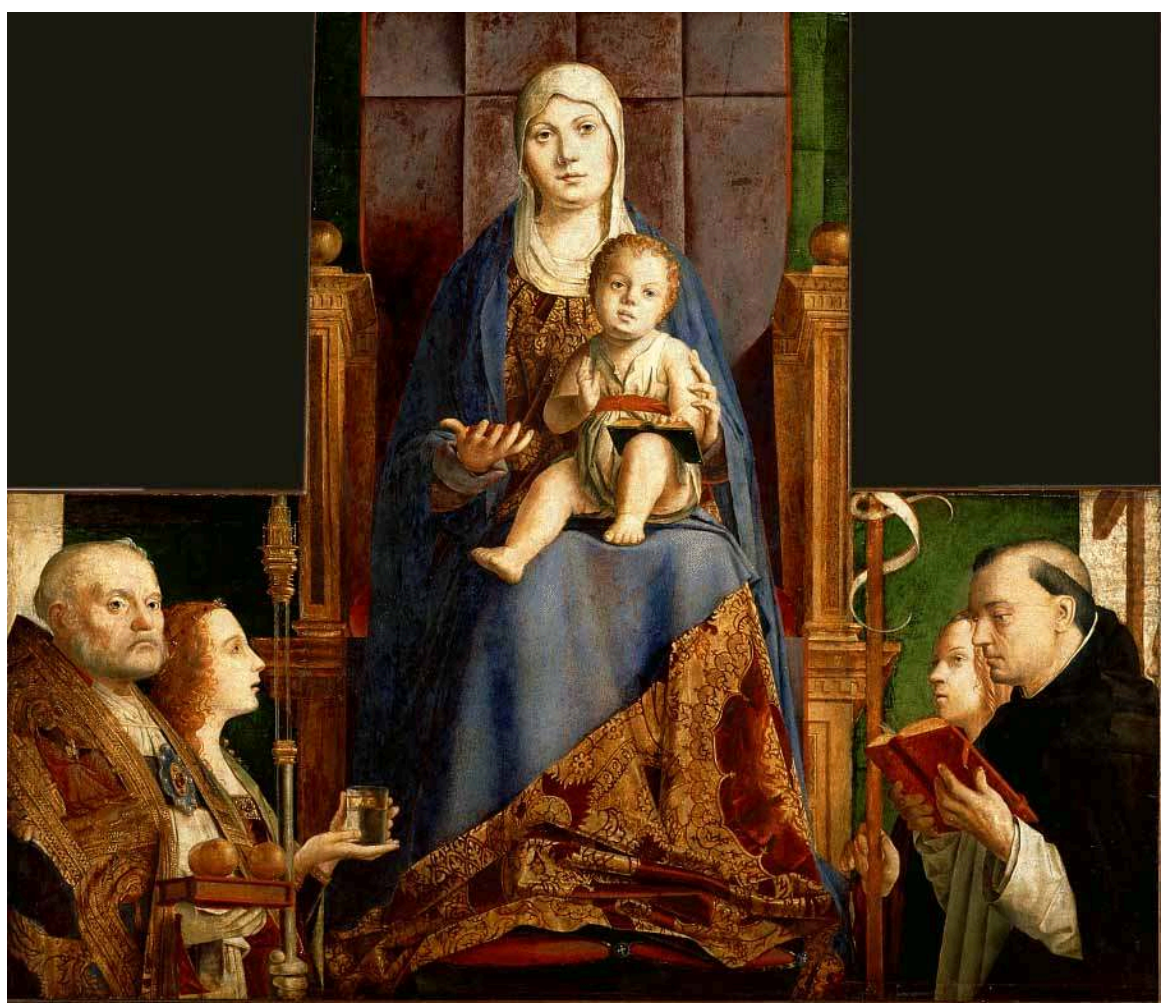

Antonello da Messina, Pala de San Cassiano, 1476, huile sur bois, $115 \times 135$ cm, Vienne, Kunsthistorisches Museum

Ici (fig. 13), les éléments de l'architecture feinte et l'architecture de l'encadrement pilastres, chapiteaux, intrados - se calquent les uns sur les autres, comme dans les exemples précédents. Dans un tour de force supplémentaire, ces éléments sont repris de l'architecture réelle de l'église ${ }^{49}$. Par le biais de cet effet, la surface du tableau, indiquée par le cadre, devient un passage, un seuil, qui donne au spectateur l'impression de partager déjà l'espace de la Vierge. Le cadre est devenu un plan à luimême, un point de rencontre.

Dans cette démarche point le lourd héritage des icônes, dont l'image est le garant d'une présence réelle, numineuse, du saint représenté. En fait, ces Madone à l'Enfant, ces Pietà - sujets de prédilection de Bellini - en sont autant d'avatars. Le thème de la Pietà descend directement de l'Imago Pietatis, dont on a vu l'importance pour Venise. Il en partage les qualités. Comme il se doit avec l'évolution artistique du Quattrocento, l'intervention de l'artiste s'affirme. Mais on ne doit pas moins voir les Pietà de Bellini comme autant d'icônes d'une nouvelle génération, intermédiaire entre l'ici-bas et l'audelà ${ }^{50}$.

Bellini réinterprète également cet autre aspect de la peinture vénitienne qu'est l'attachement aux matières luxueuses. S'il se dépouille, il est vrai, d'un faste concret, apparaissent dans ses œuvres marqueteries de marbre, tesselles dorées, étoffes brochées, traitées avec une attention qui les rend presque palpables. Il se montre très au fait des développements dans la technique du verre de Murano, comme on l'a déjà vu dans le cas du bocal que tient Nicodème. Du reste, la coupe devant le Christ dans le Jardin des Oliviers, où apparaissent comme des traits d'émaux blancs ${ }^{51}$ ou le récipient 
dans la main de Lucie dans le Retable de San Zaccaria (fig. 14) rappellent les techniques que les verriers virtuoses ont mis au point au milieu du quinzième siècle.

Il ne s'agit pas, dans ces exemples, de trompe-l'œil à proprement parler et la matière travaillée se limite au pigment et à son liant. Pourtant, ils s'inscrivent dans cette même tradition, renouvelée par Giovanni et notamment par sa manipulation de l'huile. $\mathrm{Ce}$ nouveau médium est sans égal pour la mimesis, évoquant les volumes, leur profondeur, jusque dans leurs reflets et leurs zones d'ombre. Les deux pôles de ces effets sont parfaitement illustrés par la Pala de San Giobbe (fig. 12). Les tesselles de la mosaïque semblent resplendir de reflets réels. Les plaies de Sébastien et de François semblent infligées dans une chair tendre et palpable. François place son doigt de devant la plaie vers laquelle il invite le spectateur, avec un réalisme tel que Bellini semble indiquer que le tact peut s'incorporer dans la vue. Et, effectivement, le spectateur qui se plait à s'attarder dans ces atmosphères lumineuses, serait tenté de les toucher, tant la malléabilité de ce médium permet à Bellini de dépasser le sculpturalisme mantegnesque pour parvenir à un moelleux plastique. Ses personnages saints semblent défier les dimensions de la simple peinture.

Dans le retable de Pesaro, ces effets de l'optique et de l'haptique convergent en un effet vertigineux. Toutes les Pietà de la mouvance vénitienne dans les années 1460-90 s'efforcent comme en concurrence à rendre, à re-présenter, la plaie du côté, sacrée entre toutes, «d'ou sortaient de l'eau avec le sang » selon l'Évangile. Dans le panneau qui nous occupe, seule cette plaie s'offre à notre vision. À peine un peu de pigment rouge vient colorer le liant gras que Bellini a laissé couler en épaisseur sur la surface, parfois en simple trace transparente. Par là-même, la surface semble s'animer, se mouvoir devant nos yeux, comme si l'image se mettait miraculeusement à saigner sang et eau, conformément à l'Écriture. Mieux, tout se passe comme si l'image se mettait à sécréter ce qui la fait se matérialiser.

\section{Paysage mental, pensée dévotionnelle}

41 Avant d'aller plus loin, il convient de situer plus fermement le contexte spirituel du tableau. Qu'en est il au juste de ces huiles, de cette scène, et de ces personnages qui y figurent? Que peut on deviner, au moins indirectement, des pratiques cultuelles qui s'y articulent?

Dès le quatorzième siècle, un commentateur prend en exemple la fabrication d'un portrait et glose les "vertus", au double sens pratique et métaphorique, de l'huile. Cette substance qui sert au peintre est mise en parallèle avec «l'huile de la miséricorde» et "l'huile dans le demeure du juste» qu'évoque Proverbes 21. Par analogie, le peintre se trouve implicitement lié à un rôle sacerdotal, en manipulant les huiles sacrées ${ }^{52}$.

43 Même sans jamais avoir entendu un tel rapprochement, un artiste maniant l'huile avait affaire avec une substance dont les racines sacrales remontent selon toute probabilité jusqu'aux temps les plus reculés. La pensée chrétienne hérite des conceptions hébraïques qui font de l'huile - ce liquide qui ne s'évapore pas - offrande, sacrifice, marque d'élection. Dans le Nouveau Testament, si Jésus est l'élu, le fils de Dieu envoyé comme holocauste, cela est fidèle au sens même du titre Christ, l'oint. Des onctions, il en reçoit plusieurs. Elles ponctuent les Évangiles et sont souvent confondues entre elles. 

Béthanie et verse d'un vase d'albâtre - qu'elle casse selon Marc - un onguent coûteux, pour oindre la tête de Jésus. Face aux disciples qui maugréent devant ce gaspillage, Jésus la défend, explique qu'elle l'aurait fait en prévision de son enterrement ${ }^{53}$. Chez Luc, une femme désignée comme pécheresse s'introduit lors d'un repas chez un Pharisien avec un vase d'albâtre, d'où elle verse un parfum sur les pieds de Jésus. En embrassant les pieds, elle les lave de ses larmes et les essuie de ses cheveux. Le Christ loue cette manifestation de son amour et pardonne ses péchés ${ }^{54}$. Pour Jean, cette femme est Marie, la sœur de Marthe à Béthanie, donc celle qui émeut les Christ aux larmes, juste avant qu'il ressuscite leur frère Lazare ${ }^{55}$ et qui, chez Luc, aime à s'asseoir aux pieds du Seigneur en l'écoutant ${ }^{56}$. Jean fait état d'une onction supplémentaire de la part de cette même Marie de Béthanie, sur sa tête, et cette fois encore, dit Jésus, en prémonition de son enterrement ${ }^{57}$.

Dès saint Augustin, ces différents épisodes d'onction jettent les bases de ce qui deviendra la théologie sacramentelle. L'évêque d'Hippone exprime la gémellité que nous avons constatée plus haut entre le vase d'onguent et la plaie qui suinte l'eau et le sang. Le Christ, explique-t-il, est le vase d'albâtre rempli de parfum qu'il fallait briser pour qu'en sorte l'huile propre à guérir la créature, malade de sa séparation d'avec son Créateur ${ }^{58}$. Ces images reviennent constamment chez les commentateurs postérieurs. Bonaventure n'est qu'un exemple, mais particulièrement utile pour nous. Théologien de référence pour tous les courants franciscains, ses écrits connaissant un regain certain au cours des années 1470, dû à la campagne pour sa canonisation dans laquelle Venise joue un rôle important ${ }^{59}$. Citant saint Augustin, il explique la relation entre sacrement et Passion, par le biais du sang qui devient l'huile: : [...] tous les sacrements sont dits tirer leur efficacité de la Passion du Christ. Aussi, selon Augustin, "du côté du Christ dormant se sont écoulés les sacrements" lorsqu'en a coulé le sang et l'eau "au milieu de la place" c'est-à-dire l'Église qui est le corps mystique, afin que nous soyons vivifiés par lui ${ }^{60}$.

46 L'huile est la cause matérielle du sacrement, signe sensible de la grâce divine. Du baptême à l'extrême onction, ces rites ponctuent la vie chrétienne, indiquant le passage d'un état à un autre. Ils marquent, à chaque fois, l'appartenance du fidèle au corps mystique du Christ, c'est-à-dire l'Église. Consacrées le jeudi saint, les huiles sont également employées dans les sacramentaux : exorcisme, réconciliation des hérétiques, consécration de mobilier liturgique. L'Église orientale oint également les crucifix. Certains d'entre ces crucifix, tout comme certaines reliques, et même les images des saints, pouvaient exsuder une huile miraculeuse. Les pèlerins se plaisaient à récupérer ces sécrétions dans des ampoules, et parfois même à s'en oindre ${ }^{61}$. Devant ce genre de reliques, dans les sanctuaires, devant les tabernacles, brûlaient des lampes qui se nourrissaient du surplus des huiles consacrées. Bellini avait connaissance de telles lampes. Dans la sacristie des Frari, les moines en employaient une pour illuminer sa Sacra Conversazione $e^{62}$ (fig. 11). Elles apparaissent dans les retables de San Giobbe (fig. 12) et de Sainte Catherine de Sienne (fig. 13) de San Zaccaria (fig. 14) pour indiquer la sainteté du lieu fictif.

47

Les usages concrets de cette substance reposent sur la pensée mystique qui les anime. Une thématique de l'huile sous-tend les sermons de saint Bernard sur le Cantique des Cantiques. Elle est présente, dit-il, dans le nom même du Christ quand il est dit de l'Époux que son «nom est une huile répandue » ${ }^{63}$ ou «enfermé dans un flacon » ${ }^{64}$. Ce 
liquide, qui désigne métaphoriquement le Christ, sert de source de lumière en alimentant les lampes. En onction, il soulage comme un médicament ${ }^{65}$. À son tour, l'Épouse offre l'huile comme un parfum, macéré et distillé dans le cœur ${ }^{66}$. Don réciproque, pour Bernard l'onction est un acte réflexif. «Dans l'ardeur de l'esprit, elle reste enlacée à l'oint du seigneur qu'elle ne cesse de caresser et dont toute la personne dégoutte et ruisselle d'une huile d'allégresse. De lui elle reçoit cette huile [...]; quoi d'étonnant si elle en est ointe, elle qui embrasse l'oint de Dieu ", explique-t-il ${ }^{67}$. Le cistercien fait se profiler derrière l'Âme-Épouse les différentes facettes de la femme aux onguents ${ }^{68}$, développant une tendance présente dès Hippolyte de Rome.

On retrouve un même investissement théologique de l'huile chez Bonaventure. Pour lui, l'huile est le charisme de l'Esprit Saint ${ }^{69}$. L'onction, qu'il associe étroitement avec la notion de devotio, indique une rencontre voire une union entre Créateur et créature ${ }^{70}$. "Mets de l'huile dans tout vase, car l'huile est la dévotion de l'esprit »" Elle est matière du sacrement, lui-même "récipient » dont le source est le Christ, celui qui est oint $^{72}$.

Bellini mêle donc à ses pigments une matière qui ne peut être aussi anodine que l'œuf, la colle ou l'encaustique. Il entre en contact avec une substance chargée de sens sacral, concrètement et métaphoriquement. Qu'en est il des personnages qu'il représente, tout comme lui, touchant l'huile?

Des trois dolents qui peuplent son tableau, l'histoire de la pensée chrétienne n'a pas réparti son attention de façon égale. Joseph d'Arimathie apparaît dans les quatre évangiles canoniques comme un homme influent, membre du Sanhédrin qui obtient le corps du Christ et lui donne le sépulcre. Seul Jean fait participer ce personnage à l'embaumement. Il figure dans certains évangiles apocryphes, et la tradition voulait qu'il ait accompagné la Madeleine avec Marthe et Lazare dans le sud de la France. Làdessus, il quitte le champ de la stricte tradition chrétienne pour se retrouver lié aux Contes du Graal.

51 Nicodème, pharisien lui aussi, accompagne son compère dans la narration de la Passion, apparaissant au moment de l'Ensevelissement, quand il apporte cent livres de myrrhe et d'aloès pour la dépouille. Le vrai temps fort du personnage, pourtant, se trouve dans le troisième chapitre de Jean. Nicodème vient de nuit questionner Jésus qui lui explique que « Dieu a donné son fils unique [...] ; qui croira en lui ne périra point mais aura la vie éternelle ». De plus, dit-il, pour accéder à cette nouvelle vie, il faut renaître, non pas du sein de sa mère, mais par l'eau et l'Esprit. Comme le Baptême du Christ suit immédiatement cette conversation avec Nicodème, le personnage s'est imposé dans la mise en place de ce sacrement. Bernard de Clairvaux, Hugues de Saint Victor, et Augustin $^{73}$ avant eux évoquent nécessairement ce personnage pour parler du rite par lequel l'Église, par le sang et l'eau de la plaie du côté, accouche du croyant dans le corps mystique du Christ. Cette idée semble intuitivement avoir été intégrée dans une légende tenace du Moyen Âge qui fait de lui le créateur du crucifix de Beyrouth déjà mentionné. L'objet tomba aux mains de juifs malveillants. Quand ils le percèrent au côté avec une lance «le sang et l'eau en sortirent en abondance et un vase qu'on mit pour les recevoir fut rempli». Avec ces fluides, les malades furent oints et guéris, et en témoignant de ce miracle, les Juifs «reçurent le baptême et la foi ». Il y a chez Nicodème, donc, une réflexion sur le sacrement, sur le passage de la mort à la vie, symbolique ou réelle, passage marqué par l'eau et le sang, la myrrhe et l'aloès, c'est à 
dire par des fluides sacraux. Pris ensemble, ces leitmotive renvoient au troisième acteur de la scène de Bellini ${ }^{74}$.

Le personnage de Marie-Madeleine - fusion des différentes femmes aux parfums repose sur une réflexion théologique plus complexe encore. Comme on l'a vu, les similarités entre les différentes onctions avaient constitué une énigme pour les premiers commentateurs qui parfois attribuaient ces actes à une seule et même femme. Avec le temps, chez Ambroise et Augustin, la tendance s'accentue. Sous la plume de Grégoire le Grand, un autre glissement s'entérine. Cette Marie aux parfums se greffe sur Marie de Magdala que le Christ a guéri des démons et des infirmités. Devenue sa fidèle, elle reparait au pied de la croix, puis pleurant devant le tombeau. Venue pour oindre le cadavre, elle devient premier témoin du Christ ressuscité, qui la charge de diffuser la bonne nouvelle ${ }^{75}$.

Si l'exégèse critique a depuis dénoué l'écheveau des fils textuels qui se nouent en Marie-Madeleine, on peut souligner certains des motifs qui ont mené à la création du personnage. D'une part, nous y avons insisté, l'onction unit entre elles les différentes femmes, tout comme la même association identifie la figure composite comme l'Épouse ${ }^{76}$. La familiarité existant entre Jésus et Marie vient ensuite relayer cette impression de cohésion. Le Messie prend ouvertement sa défense face aux apôtres ; elle est l'initiée de ses enseignements, de ses actes de résurrection. Cette intimité se manifeste physiquement. On la retrouve à ses pieds (ou par extension au pied de la croix). Devant le sépulcre, la scène tourne autour du contact physique, fut-il frustré par l'injonction Noli me tangere. Mais ce sont les onctions qui, par-dessus tout, expriment cette proximité privilégiée, tactile, qui caractérise leur relation.

Finalement, le tout est étayé par une pensée du trépas. Il incombe traditionnellement aux femmes de s'occuper des défunts et c'est ainsi que le Christ explique les onctions, situées en général au début du cycle de la Passion. La Madeleine accompagne le Christ pendant son supplice, veut soigner le cadavre correctement. Ainsi est-elle l'autre figure clef des deux résurrections : celle du Christ et celle de Lazare qui préfigure la première. Exorcisée, convertie, elle-même revient de loin. Quand les huiles sacramentelles - celles qui sont appliquées sur les mourants et les possédés - sont consacrées, elles le sont aussi en mémoire des parfums de la Madeleine ${ }^{77}$. En ceci, la thématique mortuaire reçoit une autre dimension encore, celle-ci mystique. Comme Nicodème, la myrrhophore figure le passage non seulement entre vie et mort, mais aussi de la mort, littérale ou figurative, à la vie de grâce.

Le terrain est fécond en interprétations associatives. De par son rapprochement avec l'Épouse, cette Marie, comme la Vierge, se glisse dans le rôle de l'Église. Elle y est destinée par le prénom qu'elle partage avec la Mère de Dieu, disent les étymologues de la première heure. Le nom de "Magdala », signifiant «tour » ou " forteresse ", vient le corroborer. Doit-on voir dans le château au fond du Couronnement de Pesaro une référence double aux deux Marie? En tout cas, dans ce personnage s'entend une figure de l'Ecclesia. Vecteur du message chrétien, Marie-Madeleine - au vase de l'huile, qui selon Bernard illumine - est celle qui a reçu la lumière pour ensuite la réfléchir, la donner aux autres ${ }^{78}$.

Le fidèle, créature pécheresse comme elle, est exhorté à suivre son exemple, à offrir le parfum de sa pénitence au Seigneur ${ }^{79}$. Selon Bonaventure, «Cette pécheresse a fourni le modèle de toute dévotion intérieure " (Sermo I sur Marie-Madeleine); «Aux pieds du Seigneur, elle l'a donc oint d'un onguent de dévotion, puisqu'elle s'est acquittée de sa 
dévotion au bénéfice de l'Incarnation et de notre rédemption [...]; de même, en effet, que l'onguent est fait de diverses substances odorifères, le Seigneur a accompli de nombreux actes pour notre rédemption. L'onguent de la dévotion les fait tous s'élever ensemble »(Sermo III sur Marie-Madeleine) $)^{80}$.

Riche de ces associations, la Madeleine a également servi de référence dans l'extraordinaire foisonnement de femmes mystiques qui, depuis le treizième siècle, apparaissaient un peu partout en Italie, à l'ombre des frères mineurs. En racontant l'histoire d'une Angela da Foligno ou d'une Marguerite de Cortone, les hagiographes cherchaient dans la figure de la sainte pécheresse un modèle, un moyen de comprendre et de faire comprendre ces extatiques aux élans passionnels et pénitents. Ces « nouvelles Madeleine » confirment une certaine image de la sainte, et de son contact privilégié avec le Christ ${ }^{81}$.

Or, l'église de San Francesco abrite les reliques de Michelina qui s'inscrit au cœur de ce courant de piété magdalénienne. Dans la première moitié du quinzième siècle, les deux sont à l'ordre du jour et liées l'une à l'autre, car on les voit rajoutées au même moment sur le sanctoral civique de Pesaro. Selon sa Vita, la bienheureuse se réclamait volontiers des liens avec la figure de l'Évangile puisqu'en vision elle aurait oint la tête du Christ. L'huile revient sensiblement dans ses aumônes comme dans ses miracles, puisqu'elle aurait, dans l'un d'entre eux, rempli inexplicablement un vase de cette substance.

Une parenté moins expresse entre les deux femmes se fait sentir dans les pratiques cultuelles qui entourent les reliques de Pesaro. Comme Marie-Madeleine avec ses parfums, Michelina guérit. Elle réserve un traitement à part pour les possédées qui reviennent avec une certaine fréquence ${ }^{82}$. Remarquons que pour la seule possession malheur qui a frappé la pécheresse de Magdala - elle agit exclusivement sur des femmes, lesquelles devront être ointes pour être réintégrées dans l'Église ${ }^{83}$. L'essentiel, pourtant, est dans la façon de faire. Ainsi qu'entre le Christ et la Madeleine, les guérisons de Michelina passent par le toucher. Les actes votifs tournent autour du tactile à l'égard des restes mortels de la bienheureuse, par le moyen d'un guichet pratiqué dans son sarcophage. Les possédées allaient jusqu'à passer la nuit dans la chapelle ${ }^{84}$.

Giovanni - ayant de la famille à Pesaro et dans les alentours ${ }^{85}$ - aurait pu avoir écho des légendes de la sainte et des pratiques des pèlerins qui venaient l'invoquer. Il est possible que cela ait joué dans son insistance sur le toucher, l'huile et le rôle de la Madeleine, voire dans la logique interne du tableau, telle qu'on la verra. En tout cas, ces approfondissements du champ associatif - des strates d'allusions comprises par la pensée religieuse - donnent de l'épaisseur à notre thèse, rendent plus lisible notre déchiffrement du tableau comme possédant un fonctionnement sacramentel.

\section{La lecture liturgique}

61 La clef de cette lecture est fournie par le processus très particulier de l'encadrement (fig. 1). Nous y avons insisté plus haut, en examinant à quel point Giovanni médite sur cet élément comme moyen de joindre les mondes physique et métaphysique. D'autres ont déjà relevé, à l'égard du seul Couronnement, la réitération systématique du dispositif. Pour Battisti, la pala obéit à une logique architectonique. Pilastres et corniches fonctionnent comme portail, comme fenêtre, qui présentent à l'œil une série de plans transversaux à franchir. La grande taille des personnages, le point de vue assez 
bas, placent le dévot fictivement à genoux, immédiatement devant le trône, selon son analyse, lieu d'ailleurs impossible à tenir compte tenu d'autres repères spatiaux. Cet agencement appellerait le fidèle à une interaction intime dans le monde d'ici-bas avec un évènement céleste, inaccessible. Le va-et-vient entre le proche et le lointain, provoquant la participation du croyant, est mis en œuvre par cette série d'écrans (Battisti en compte jusqu'à sept) qui s'encastrent les uns dans les autres ${ }^{86}$.

L'argument de Battisti se trouve étayé par l'analyse de Wilson, qui décèle dans cette succession de plans une dynamique intégrée dans l'église entière. En franchissant le seuil de l'église, le fidèle est projeté - au moins par le regard - sur un trajet axial dirigé par ce télescopage de cadres répétés. Le portail même est le premier de cette série qui encadre la nef. Le dévot suit celle-ci jusqu'à l'embrasement du jubé qui donne sur le chœur, puis traverse l'arc triomphal qui entoure le sanctuaire, qu'il remonte pour arriver jusqu'à l'autel. Ici, la pala prend le relais. Le spectateur pénètre le double cadre doré. Devant le trône, il passe par Maria-Ecclesia, fenestra coeli, pour atteindre la Jérusalem céleste. Seuil ouvre sur seuil, lieu ouvre sur lieu, dans une sainteté qui ne cesse de croître à la mesure que l'œil progresse. Cette mise en abîme sera utilisée uniquement ici ${ }^{87}$.

Les « dilatations rythmiques $»^{88}$ se prolongent dans la cimaise (fig. 2). Les montants du trône - cadre pénultième - en empruntant au centimètre près la largeur du cadre supérieur et final, opèrent ainsi le glissement vers le Christ mort entouré. Bellini utilise son support matériel pour tendre au spectateur «une invitation à se mouvoir par l'imagination entre les strates et le profondeurs diverses [...] à jouer entre la profondeur suggérée et la réelle $»^{89}$. Le motif de la tour-Église peut assurer le transfert d'une Marie à l'autre. Une fois à la cimaise, l'arrière-plan, dénoué de repère spatial empêche l'œil d'aller plus loin. Il est amené à se concentrer sur cet ensemble de figures si étrangement ordonné, jusqu'à ce qu'il s'arrête sur le cœur même de la composition : l'onction.

La polysémie de l'huile recouvre à la fois celle qui oint et celui qui reçoit l'onction. Cette substance compose Marie-Madeleine, que la tradition iconographique signale par son vase de parfum. Les huiles qu'il contient sont effectivement vouées à l'usage ecclésiastique, puisque consacrées le jour où la pécheresse aurait déversé son parfum sur les pieds du Christ. Celle-ci, illuminata-illuminatrix, l'ayant touché, l'ayant vu ressuscité d'entre les morts, est chargée de diffuser ce qu'elle sait.

La source de cette illumination est, bien entendu, Celui qui est Oint, celui dont le nom est l'huile déversée, une huile, comme dit Bernard, qui nourrit les lampes. Il est «medium » de la lumière de Dieu le Père, dit Bonaventure, un « rayon superessentiel » qui en descend. «Rayon fontal », de sa source coule «l'huile de la joie qui réjouit la cité de Dieu $»^{90}$.

La possibilité de communiquer la symbolique de lumière a certes inspiré les diverses interprétations du vase de la Madeleine. Certaines vont même au-delà de l'anecdotique. Ciselées à même le fond d'or, leurs formes - de reliquaires, de pyxides - renvoient à la liturgie, et rappellent l'équivalence qui est faite depuis Augustin entre le vase et le corps du Christ, l'huile et le sang qui y sont contenus. Il en va de même pour la matière de base, l'or. Ce métal céleste manifeste la lumière divine à celui qui le contemple ${ }^{91}$. bellinienne qui a trouvé - pour ce panneau précis - une substance plus évocatrice 
encore que l'or pour ses propriétés physiques et mystiques. Comme lui, l'huile possède de merveilleuses vertus de luminosité, mais ce vecteur dispose d'atouts que l'or n'a pas dans sa capacité d'incorporer cette lumière au sein de la couleur. Comme la Madeleine, comme le Christ, l'huile est vectrice, médium de lumière. Au propre comme au figuré, elle est un liant ${ }^{92}$. C'est elle qui relie les différentes facettes de la figure de MarieMadeleine, comme elle relie cette dernière au Christ. L'ensemble des croyants s'inspire de cette relation, voire cette religio, au sens fort. En intégrant l'Église, née de la blessure de la lance, et du liquide qui en découle, le chrétien lui-même renaît "par l'eau et l'Esprit ", intégrant le corps mystique du Christ, par l'intermédiaire du sacrement. Le signe matériel de cette grâce - c'est-à-dire l'huile - trouve ses origines dans l'eau et le sang qui sourdent du bois du panneau. Ainsi culmine l'itinéraire liturgique, scandé par les différents encadrements, de l'église à l'Église, depuis le portail de San Francesco, jusqu'à la plaie du côté.

De ce point, légèrement teint de rouge, la main de l'artiste a laissé couler, laissé sécher son liant en filets dont la transparence est démentie par leur relief. Ces épanchements outrepassent les limites du tableau comme si l'image se mettait à saigner sa substance propre. Du coup, la surface prend valeur comme plan à part entière. Le cadre n'indique pas, comme avec le Retable de Sainte Catherine de Sienne, un point de rencontre qui nie la surface pour faire abstraction d'un mur de fond. Au contraire, cette surface est incorporée dans la série d'écrans à traverser. L'œil le franchit, ou, mieux, s'y immerge, pour atteindre l'Onction, la vivre. Il pénètre la plaie du côté, destination ultime de sa trajectoire, d'où coule l'huile, en parfaite osmose entre figurant et figuré. Le trompel'œil se mue en présence réelle. Giovanni exerce ce qui s'apparente à une sorte de transsubstantiation artistique de l'huile qui coule par dessus l'autel. Le fidèle, achevant son itinéraire de l'esprit, ne peut que le recevoir.

\section{Un regard en périphérie}

\section{Bellini et la tradition visuelle franciscanisante}

La tradition franciscaine a longuement nourri les correspondances entre le regard, l'image et sa substance. Cette interaction fait même partie des origines de l'ordre, à travers l'épisode du crucifix de San Damiano qui a suscité la conversion de François. Ici s'amorce une relation entre le saint et cet objet qui aboutira, au moment de la stigmatisation, à l'identification absolue entre le poverello et le Christ en croix. Dès lors, les crucifix deviennent partie intégrante de la piété propre aux Frères Mineurs, de leur mode de communiquer le message chrétien. Il est d'ailleurs significatif que ce soient les crucifix peints des ordres mendiants - eux-mêmes des références au Crucifix de Beyrouth $^{93}$ - qui aient préparé le chemin pour le succès de l'Imago Pietatis. Ils en sont en quelque sorte les géniteurs comme l'Imago Pietatis l'est pour la Pietà ${ }^{94}$. Il y a comme une filiation dévotionnelle qui les relie et qui va, au moins avec l'Onction de Pesaro, jusqu'à l'usage symbolique du matériau.

Dans le Toscane et l'Ombrie du Duecento et Trecento, faire abstraction du support d'une image n'intéresse ni l'artiste ni le spectateur. Quand il s'agit du crucifix, il y a fortiori tout intérêt $d^{\prime} y$ insister ${ }^{95}$. Sur ces planches taillées, vissées ensemble pour former deux angles droits, l'artiste s'arrange, de par la matière et la forme, pour manifester " un rapport tautologique entre la croix en bois et le Christ sur la croix », 
pour « abolir toute distinction entre la figure et son support $»^{96}$ éveillant ainsi à vif le sentiment de piété chez le dévot.

71 La matière s'exhibe en tant que telle, mais pas à l'état brut. Tout aussi franchement se font sentir les étapes de leur construction, de leur préparation. Le bois est coupé, sculpté, poli, ensuite assemblé, recouvert de parchemin, puis de chaux avant de recevoir la peinture. Le regard du spectateur ne vient-il pas comme une couche successive dans sa fabrication? Car telle est la finalité de ces artefacts : accueillir le regard du dévot, le mener à se blottir dans les plaies, tel que l'exhorte Bonaventure. Ceci peut arriver, nous a-t-il dit, par le biais d'un identification méditationnelle avec les autres témoins de la Passion, la Vierge Marie, Jean L'Évangéliste, Marie-Madeleine, ou en pénétrant directement la plaie du côtée ${ }^{97}$.

72 En somme, une même dynamique sous-tend les crucifix des douzième et treizième siècles et l'Onction de Pesaro. D'abord, dans les deux cas, nous avons affaire à une image dévotionnelle, dont la matière est hautement significative au sein de la pensée qui l'a fait naître. Ensuite, sa raison d'être se trouve dans le regard du dévot. Celui-ci n'y pose pas simplement les yeux: il la pénètre. En se joignant aux autres témoins de l'événement, il peut participer à l'épisode sacré. Il peut aller jusqu'à entrer dans les plaies du Christ. Or ce fonctionnement particulier de l'image se niche dans les origines même de l'expérience franciscaine.

Si ces expériences semblent loin dans le temps de l'Onction de Giovanni Bellini, deux œuvres que nous avons déjà vues donnent un contexte historique immédiat à cette expérience plastico-théologique spécialement parce que leurs auteurs sont liés à Jacopo Bellini, père de Giovanni.

Nous avons parlé de l'Adoration de Gentile (fig. 6), maître de Jacopo, et de l'usage de l'or comme représentatif de la pensée matérielle de l'école vénitienne. Ici, les rois offrent à l'Enfant Jésus de l'or, de l'encens et de la myrrhe dans des pyxides élaborés, dont les formes pointues font écho aux gâbles sculptés du cadre. L'or qu'utilise l'artiste souligne non seulement leur contenu mais évoque aussi la vaste effusion de ce métal qui remplit le retable au point d'en faire - comme nous l'avons déjà dit - autant un travail d'orfèvre qu'une œuvre picturale. En rappelant qu'il avait été commandité par un banquier richissime pour la sacristie de Santa Trinita, on peut voir le parallèle entre la propre offrande du commanditaire et celle des rois-mages ; suggérer, à travers cet acte de dévotion, une interférence tautologique possible entre thème et matière sacrée, où même le cadre participe à une " lecture liturgique » comparable en ces points à ce que l'on observe dans l'Onction de Giovanni Bellini.

Le Polyptyque de Michelina (fig. 5) en est encore plus proche : dans la chapelle voisine. Accosté à l'autel de la bienheureuse thaumaturge, le retable aurait pu servir d'inspiration pour Giovanni Bellini à plus d'un titre. Les fidèles venaient de loin pour contempler cette œuvre qui était sûrement la plus prestigieuse que San Francesco ait jusque là possédée. Par conscience professionnelle, Bellini aurait certainement voulu la dépasser, à plus forte raison puisqu'il aurait été chargé d'honorer dignement le maîtreautel. Rappelons aussi que le polyptyque était de la main d'un ancien collègue de son père, qui avait expérimenté ici des procédés insolites, ce qui ne pouvait qu'accroître son intérêt aux yeux de Bellini. A-t-il déjà vu ce mélange des dimensions qui fait surgir la figure principale? Un autre exemple dans la génération suivante, nous avons dit, fut exporté de Venise à Pesaro par le concurrent de Bellini, Antonio Vivarini (fig. 9). 
Quoi qu'il en soit, Michelina figure parmi les saints en pilastre, qui eux-même - en vertu de sa présence - rappellent le polyptyque de Iacobello. Les deux œuvres offrent des similarités, où thème et rite se recoupent. Chez Iacobello, un dévot cherchant une métamorphose physique touche concrètement une sainte qui virtuellement a oint le Christ, qui guérit les possédés. La cimaise de Giovanni emploie cette sainte exorcisée, qui avait concrètement oint le Christ, pour offrir au fidèle un toucher virtuel de Jésus, en vue d'une métamorphose intérieure.

Le parti haptique de Iacobello, de la tradition vénitienne, donne à voir, à sentir, la présence tridimensionnelle, physique, de la sainte. Comme le croyant passe la frontière du sarcophage pour y faire entrer sa main dans l'espace de la sainte, de même elle surgit du support du retable, d'entre les colonnes, dans l'espace du croyant. Cette interaction annonce celle de l'œuvre de Giovanni où l'huile dépasse les limites du tableau, déborde la surface, s'offre aux yeux du spectateur en une dynamique rituelle. Ces conjugaisons des pratiques cultuelles et des choix plastiques obéissent à une même méditation sur l'idée de profondeur et de surface, espace du dévot et espace du divin.

\section{Bellini, Mantegna et Antonello et le « dialogue pictural»}

On peut continuer à élucider ces procédés en les confrontant à des œuvres plus strictement contemporaines. Hans Belting a admirablement mis en lumière l'ampleur et la fécondité de ce qu'on pourrait appeler un « dialogue pictural » entre Bellini et son entourage, plus précisément Andrea Mantegna et Antonello da Messina sur le thème de la Piet $^{98}$. On suit en détail ces fructueuses "conversations", répliques et contrerépliques autour du renouvellement d'un genre. Ces échanges deviennent un champ pour se mesurer aux autres, les dépasser, voire se dépasser soi-même. Tant et si bien que "parfois ils sont le sujet d'une véritable polémique avec un autre artiste rival: nous arrivons à comprendre pleinement le sens seulement quand nous découvrons quelles étaient les autres peintures que Giovanni Bellini entendait dépasser ${ }^{99}$.

L'œuvre qui nous fournit peut-être le plus de comparaisons éclairantes sur le panneau de Bellini ne vient pas d'un artiste rival, mais de sa propre production. En effet, la Pietà de Brera (fig. 16) offre de frappantes analogies qui donnent à penser qu'en $1470^{100}$, il jetait les bases de l'expérience culminante de l'Onction qu'il peindra quelques années après. Résumons les faits de son analyse ${ }^{101}$ qui, par la suite, informera celle de l'Onction. 
Fig. 16

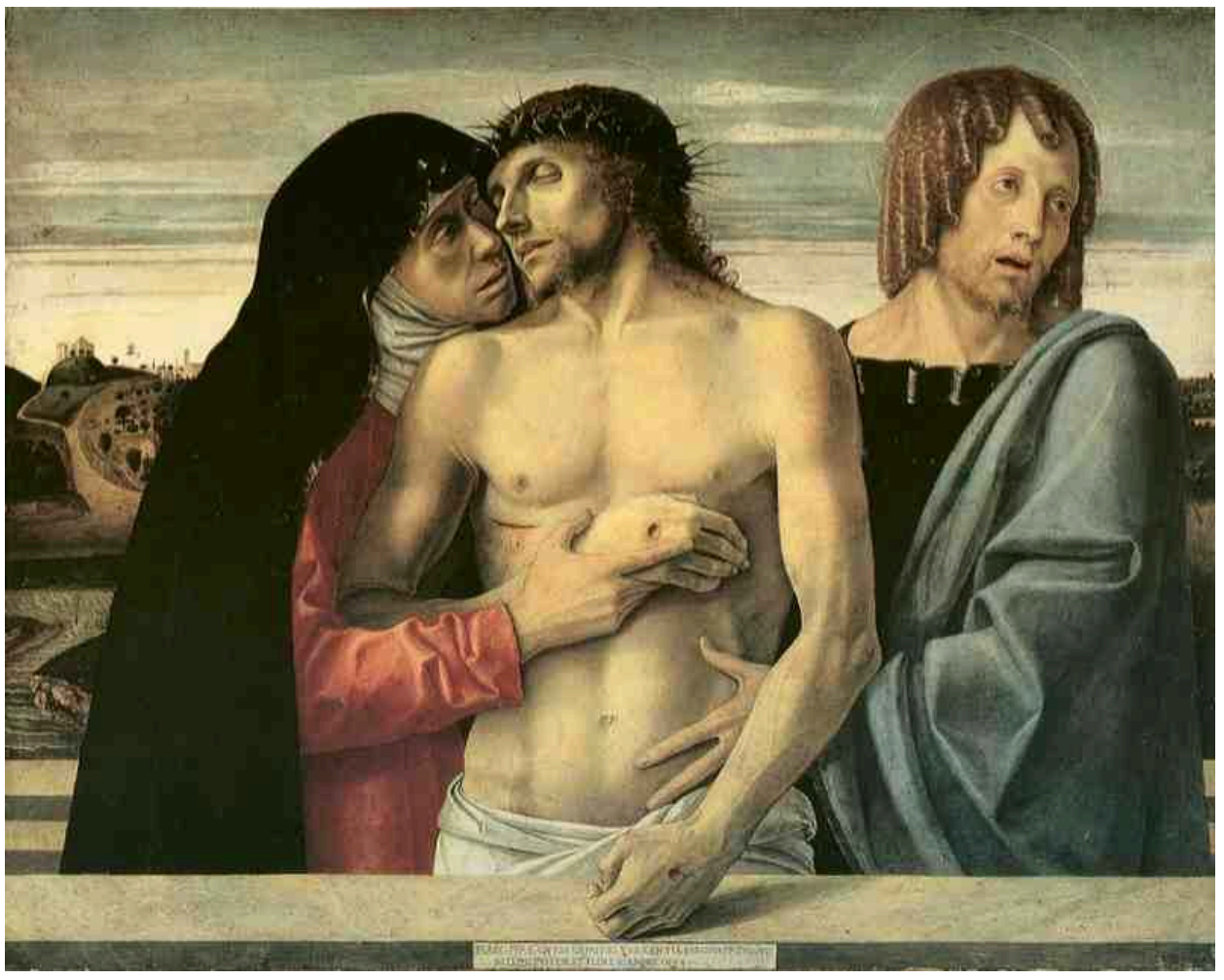

Giovanni Bellini, Pietà, v. 1470, tempera sur bois, 86 x 107 cm, Milan, Pinacothèque de Brera

80 Le Christ mort est soutenu par sa mère et par Jean l'Évangéliste, dont les visages sont marqués par les larmes. La Vierge tient la main droite de son fils, mettant cette plaie en parallèle avec celle du côté, qui s'écoule doucement. Le bras gauche retombe sur le parapet de marbre, qui se révèle être le tombeau du Christ, dans lequel se trouve cette "triple icône " ${ }^{102}$. Sa main tombe de telle façon qu'elle indique, en quelque sorte, un détail dont dépend le sens de l'œuvre.

81 Il s'agit d'un cartellino en trompe-l'œil. Son texte s'inspire librement de Properce, dans lequel le poète crée une épitaphe pour un ami défunt. Par cette épitaphe, le poète peut imaginer que son ami, par delà la mort, lui adresse la parole, et après lui, à des générations futures : «Pourquoi à notre gémissement détournes-tu tes yeux gonflés de larmes?» (Quid nostro gemitu turgentia lumina torques) De ce bref texte, Bellini tire la formule suivante: "À peine ces yeux gonflés de larmes pousseraient-ils des gémissements, l'œuvre de Giovanni Bellini pourrait pleurer » (Haec fere cum gemitus turgentia lumina promant / Bellini flere poterat ioannis opus) ${ }^{103}$.

Selon la logique du tableau, les mots que prononce le défunt sont placés dans la bouche du Christ mort. Par le biais de cette épitaphe, il s'adresse à saint Jean, qui, en effet, s'en détourne les yeux gonflés de larmes. Celui-ci, en dirigeant son regard hors de l'espace du tableau, se donne au spectateur comme moyen d'entrée. Le dévot qui contemple le tableau peut s'identifier à lui, pleurer avec lui. En prenant la relève du disciple bienaimé, le dévot se joint aux générations futures qui succèdent à Jean, destinataires ultimes des mots de l'épitaphe.

83 Les mots sont agencés de telle façon que le prénom de Giovanni sur le cartellino se trouve spatialement en relation avec cette figure de saint Jean. Bellini, tirant parti du 
prénom partagé, se reconnaît dans son saint onomastique. Par cette identification, il se place parmi les dévots, les générations futures, tout en se plaçant nommément dans le rôle d'un des protagonistes de la scène. De la sorte, il devient destinataire de sa propre création ${ }^{104}$. Car le cartellino, qui l'indique simultanément comme acteur et comme spectateur, est également le moyen par lequel il laisse la trace de sa présence créatrice. Le papier déclare l'œuvre fruit de sa main, pointe son travail de peintre. En faisant retomber la main du fils de Dieu, c'est-à-dire le Créateur créé, sur cette déclaration, Bellini met en exergue l'ambiguïté du rôle de l'artiste dans le fonctionnement de l'image dévotionnelle. Ici, il est à la fois créateur, destinataire et médiateur.

Pour finir avec ce résumé, la reformulation de la phrase, telle que l'a conçue l'artiste, comporte encore une bizarrerie. Si Jean et le spectateur pleurent, selon le texte c'est l'image qui " pourrait pleurer ». La Pietà de Brera serait donc un tableau qui se mettrait à répandre des larmes, à la suite des images miraculeuses évoquées plus haut. Ce miracle, de la main de Giovanni, témoigne ainsi de la «force toute divine» de la peinture, comme disait Alberti ${ }^{105}$.

En ré-examinant la cimaise de Pesaro à la lumière de cette discussion, des parallèles saisissants se font sentir. Ici Bellini s'exerce encore plus subtilement que dans le panneau de Brera. Néanmoins, les différents niveaux de lecture s'éclaircissent en remplaçant l'écriteau par l'usage de l'huile. L'artiste ne recourt pas au mode discursif $\mathrm{du}$ cartellino pour étiqueter les rôles. Cette Onction, de par son sujet, de par la matière, indique la Madeleine qui oint et Nicodème qui tient les huiles.

La sainte est homologue de Jean en tant qu'agent d'entrée dans le tableau, bien que cela ne se passe pas par les pleurs empathiques. Malgré la tradition, aucune larme ne tombe de ses yeux, comme si tout écoulement ne pouvait provenir que de la seule plaie du côté. Du reste, le dévot ne peut accéder par un regard extérieur, puisque tous sont absorbés par le geste qui les commande et qui régit la composition du tableau. En revanche, la place apparemment si énigmatique de la Madeleine sert à la mettre au plus proche du spectateur. Au bord du cadre de ce panneau placé si haut, elle permet au dévot d'obéir aux écrits pieux, et de passer par elle pour vivre ce moment de la Passion. Avec elle, il peut lui aussi oindre le Christ. Cette onction étant, comme le dit Bernard, réciproque, en s'identifiant à elle, le spectateur est à son tour oint.

De même que dans le panneau de Brera, la main morte du Christ attire l'attention sur la clef de la lecture de l'image. Elle reçoit l'huile. Comme le cartellino sert de signature, en soulignant l'acte créateur de l'artiste, l'huile ici fait référence au travail pratique de peindre. Avec cette substance Bellini fait apparaître aux yeux des fidèles ce corps du Christ ; il le matérialise. Comment, à partir de là, ne pas penser que l'artiste, lui aussi, oint le Christ? En bon chrétien, il suit l'exemple de cette Madeleine inventée sur mesure, qui touche l'huile, mais il se met aussi à la place de celui qui les tient, Nicodème, l'homme qui a porté aloès et myrrhe pour oindre le corps du Christ, créateur du crucifix de Beyrouth dont l'eau et le sang seront recueillis et conservés «dans des ampoules de cristal et de verre $»^{106}$. Avec cette Onction, Giovanni Bellini se pose en nouveau Nicodème ${ }^{107}$. Comme annoncé par la Pietà de Brera, cette œuvre de la main de Giovanni qui "pourrait pleurer », le Vénitien se veut créateur d'une image qui éclate en humeurs sacrées agissant sur ceux qui l'ont vu, qui en ont été touchés ${ }^{108}$.

Sous l'effet d'une sorte de sacerdoce artistique, l'Onction de Pesaro saigne, suinte, et ceci devant nos yeux, cette huile qui le compose, qui lui confère d'ailleurs tout son moelleux, sa palpabilité qui invite le spectateur à y toucher. En répandant ces fluides 
sacramentaux, elle oint. Il se passe ici une espèce de sacerdoce artistique. Celui qui contemple avec dévotion cette image doit passer par la surface, la pénétrer, et se trouve, à son tour, par l'office du peintre, oint.

Quelques œuvres des rivaux en question ne semblent pas, au premier regard, convenir à un débat sur la Pietà. Mais elles expliciteront les thèmes et les bases structurales du panneau qui nous occupe. Tournons notre attention vers le surprenant Christ Mort d'Andrea Mantegna (fig. 17), ensuite vers les expériences sur l'emploi de l'huile par Antonello quand il s'adresse aux spectateurs de culture vénitienne (fig. 15).

Fig. 17

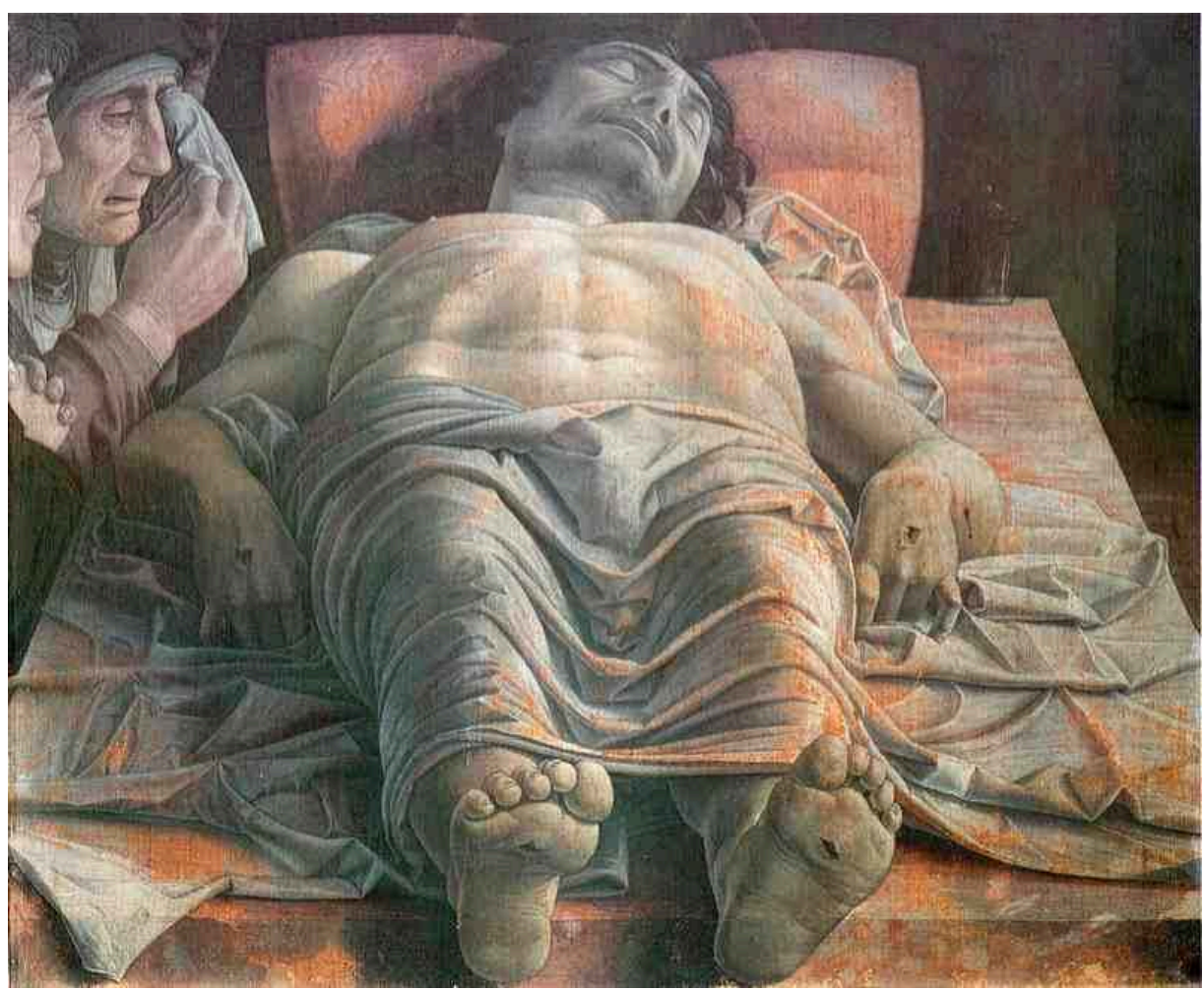

Andrea Mantegna, Christ Mort, v. 1460-1470 ?, tempera sur toile, 68x81 cm, Milan, Pinacothèque de Brera

Si la première comparaison se fonde surtout sur un lien iconographique et les autres sur l'usage symboliquement investi d'un médium, le dénominateur commun est une réfléxion sur le sang christique. Ceci n'est ni banal ni gratuit, mais s'insère dans un vif débat qui fait rage entre franciscains et dominicains sur son statut cultuel après la Crucifixion et avant la Résurrection ${ }^{109}$. C'est la relique du sang christique apporté par Joseph d'Arimathie à Mantoue qui déclenche la fureur en 1462.

\section{Mantegna et la configuration d'une Onction}

91 À Mantoue même, l'œuvre de Mantegna place le Christ selon un raccourci dramatique nouveau, étendu sur une dalle, les pieds vers le spectateur (fig. 17). Avec une extrême économie de détails, le corps est arrangé de sorte à laisser distinguer les cinq plaies. Chaque béance force l'attention: celles des pieds prennent un aspect épouvantable, au point d'en provoquer le malaise. L'invenzione de Mantegna ressemble à celle de Bellini 
en ce qu'elle précipite le spectateur dans une relation intime avec les plaies. Mantegna jette le dévot dans un violent face-à-face avec la chair déchirée, plaies grandes ouvertes comme la bouche du dolent dans l'obscurité. L'artiste contraint à leur faire face, à participer émotionnellement à l'horreur de la scène ${ }^{110}$.

L'efficacité de la mise en scène distrait des autres éléments de l'image. D'un côté du cadavre, Jean l'Évangéliste et la Vierge Marie, se lamentent. Une troisième personne dans la pénombre jette ses bras vers le haut. Elle est comme réduite à - ou plutôt condensée dans - son cri. Les règles de l'iconographie permettent de l'identifier. Sa position derrière le Christ mort, entourant la Vierge avec Jean l'Évangéliste, son geste, son cri, le vase d'onguent tout proche : ces indices concourent à y reconnaître MarieMadeleine. Ainsi, en retournant la scène de quarante-cinq degrés, on verrait le corps du Christ étendu devant sa mère, entre la Madeleine et Saint Jean : une Pietà.

La dalle sur laquelle le cadavre s'étend vient affiner cette interprétation. Relique byzantine, elle aurait été pour toujours tachée par le sang du Christ au moment de son embaumement $^{111}$. En ceci, le seul autre objet du tableau, lui aussi fait de marbre, prend toute sa pertinence : le vase d'onguent, pendant de Marie-Madeleine. Ainsi Mantegna, à l'instar de son beau-frère, infléchit une Pietà traditionnelle. Par le biais de quelques détails significatifs et une composition étonnante, il la fait glisser vers une Onction qui force l'interaction contemplative ${ }^{112}$. D'ailleurs, ici aussi, comme dans la Pietà de Brera, la figure de Saint Jean renvoie personnellement à l'artiste lui-même ${ }^{113}$.

Si l'œuvre de Mantegna, trouvée dans son atelier à sa mort, est difficilement datable, les beaux-frères se suivaient de près, et ces deux images s'élucident mutuellement et corroborent réciproquement leur lecture iconographique. Le nœud d'œuvres dans lequel s'inscrit l'Onction de Bellini, se trouve ainsi resserré autour d'une méditation particulière et participative sur les plaies et l'onction.

\section{Antonello : du bon usage de l'huile}

Après cette mise au point iconographique, une comparaison avec Antonello permettra de mieux appuyer notre propos et la réflexion sur la signification de la substance matérielle de l'huile. Au cours des années 1470, Antonello partage avec Bellini un intérêt similaire pour les humeurs christiques dans une série de Ecce Homo. Il explore le thème au moins six fois, en parallèle avec ses propres expériences sur la Pietà ${ }^{114}$. Celui qui date de son séjour vénitien offre une vision rapprochée de la tête de Jésus en troisquarts ${ }^{115}$ (fig. 18). La corde au cou et la bouche ouverte, il lève les yeux vers le ciel, comme pendant la montée vers Golgotha. Larmes et gouttes de sang perlent sur les tempes, les joues, le cou. De par leur traitement à l'huile, elles permutent sur la surface, semblent se changer les unes dans les autres, rappelant un Christ pleurant, voire suant, le sang ${ }^{116}$. Tout comme Bellini matérialise dans l'huile l'eau et le sang coulant de la plaie du côté, Antonello, avec le même médium, nous rend témoins intimes de la physiologie miraculeuse du fils de Dieu. 


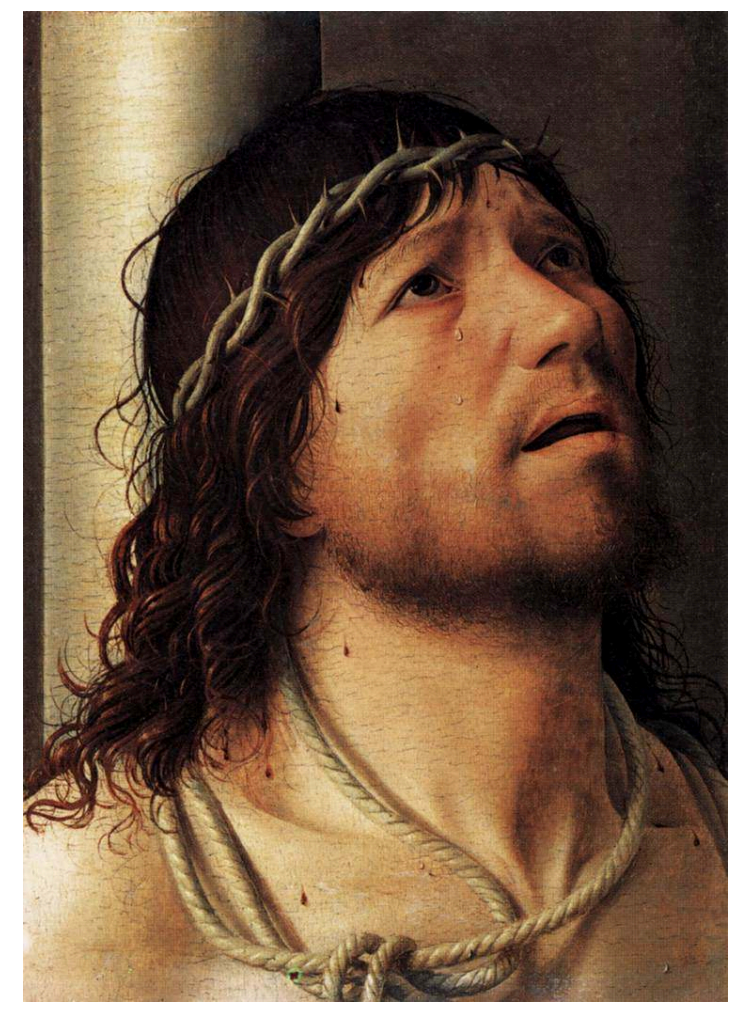

Antonello da Messina, Ecce Homo, v. 1476, huile sur bois, 29,8 x 21 cm, Paris, Louvre

Par l'intermédiaire de ces fluides, les correspondances entre les deux tableaux se poursuivent jusque dans les bases structurales. En tant que portrait du Christ souffrant, l'Ecce Homo est le proche parent de l'Imago Pietatis, et plus proche encore de la Véronique, que nous avons mentionnée au passage plus haut ${ }^{117}$. L'histoire de ce voile se trouve en germe dans un passage de l'Évangile et devient, à travers le Moyen Âge, une légende vivace. Elle raconte que le Christ aurait laissé la ressemblance de son visage sur le voile de la sainte après que celle-ci l'aurait essuyé. Relique d'abord, le voile est aussi icône, la vera icona, comme révélé dans le nom de Véronique. Plus encore, il s'agit d'une image acheiropoète ; aucune main d'artiste ne s'est interposée dans ce portrait, pour compromettre son pouvoir numineux. En outre, le portrait miraculeux ne tombe pas du ciel comme tant d'autres. Pigment et liant sont la sueur et le sang du Christ. Dès lors, les images aux épanchements mystérieux - madones qui pleurent et crucifix qui suintent - trouvent leur source dans la Véronique. Comme l'Ecce Homo, la Véronique est investie de cette méditation sur les effusions sacrales qui entérinent un fonctionnement iconique, précisément comme dans le cas du panneau de Bellini. Cela ne peut que mieux parler à une réception vénitienne, avec leur tradition d'images miraculeuses, et une culture visuelle qui investit fortement la surface picturale et son interférence haptique avec l'espace du spectateur.

Une dernière comparaison apportera quelques pensées finales. La Sacra Conversazione ${ }^{118}$ que peint Antonello da Messina pour l'église San Cassiano (fig. 15) a été qualifiée «de le piu ecxelenti opere di pennello che abia Ittalia e fuor d'Ittalia $»^{119}$. Il est vrai, pour expliquer toute exagération possible, que c'est le commanditaire qui parle et son interlocuteur n'est autre que Galeazzo Maria Sforza, dans le but de justifier le retard que prend le peintre à se rendre à la cour de Milan. Sa composition innove en proposant une Sacra 
Conversazione qui se développe à la verticale dans un champ unifié, ne faisant plus appel aux sous-divisions des polyptyques traditionnels ${ }^{120}$. Il s'agit aussi de ce qui est probablement la première peinture italienne entièrement faite à l'huile qui aurait trouvé sa place dans la Lagune. L'image a certainement dû frapper fort. Giovanni Bellini n'était sans doute pas des moindre de ses victimes, comme révèlent ses compositions immédiatement postérieures, les retables de Sainte Catherine de Sienne (fig. 13) et de San Giobbe (fig. 12) y étant étroitement liés ${ }^{121}$.

De la force de cette impression découle, en partie, la difficulté à dater le retable de Pesaro, étant donné la ténacité de la légende selon laquelle Bellini aurait dérobé à Antonello le secret de la peinture à l'huile. Dans cette optique, le retable de San Cassiano servirait de terminus post quem pour le retable de Pesaro. Cette histoire, et le raisonnement qu'elle entraîne, ont été amplement démentis. Néanmoins, il se peut que le retable d'Antonello ait effectivement précédé celui de Giovanni, et que dans la tradition de dialectique picturale entre les peintres de la lagune, le retable de Pesaro soit une réponse au retable de San Cassiano qui était adressé en partie à Giovanni luimême

Quand Antonello arrive dans la Sérénissime et entreprend cette pala, il cherche à s'acclimater à son nouveau public. Il veut faire du vénitien, ce qui, en somme, revient à faire du Bellini. Même dans son état fragmentaire, la lumière diffuse, la tendresse solennelle, le silence profond, le choix même du sujet, font immanquablement songer à celui qui règne en maître sur la peinture de cette ville ${ }^{122}$. L'effet est si bien réussi qu'au milieu du dix-neuvième siècle, le retable fut vendu comme œuvre du maître vénitien. Il a fallu attendre une soixantaine d'années pour que Bernard Berenson y discerne définitivement la main d'Antonello ${ }^{123}$.

100 Tout en gardant à l'esprit cette parenté de style, allons plus loin dans ce sens en resserrant l'attention sur deux éléments iconographiques: Marie-Madeleine et tout particulièrement son vase d'onguent ${ }^{124}$. Ce petit bocal de verre semble anodin par sa simplicité. Seul un fin trait d'or vient souligner sa forme cylindrique. Il peut paraître, si je puis dire, transparent. C'est précisément là où il ne l'est pas. Comme le bocal dans le panneau de Giovanni, un tel vase est complètement insolite dans l'iconographie de la Madeleine ${ }^{125}$.

Dans un premier temps soulignons qu'un verre doté d'une si parfaite transparence doit retenir l'attention. Cette qualité n'est alors que très récemment perfectionnée à Venise, depuis une vingtaine d'années. Baptisé cristallo, ce type d'ouvrage, avec le rosechiero, le lattimo et les nombreuses autres inventions muranaises, fait fureur dans les cours européennes. Une Isabella d'Este, un Philippe II, les collectionnent au même titre que les chefs d'œuvres sur toile ou sur panneau qui viennent de la cité des doges. Une visite aux ateliers des fiolarii s'imposait à tout voyage diplomatique ${ }^{126}$. Le créateur de ce type de verre, Angelo Barovier " qui fait de si beaux travaux en verre cristallin ", se retrouve hôte d'honneur dans la cité idéale que Filarete invente pour Francesco Sforza ${ }^{127}$. Imiter de tels objets relève de cet effort d'acclimatation, voire de louange, de la part d'Antonello à l'art de la Lagune.

Par l'aplomb avec lequel il en réussit l'imitation, en revanche, le maitre sicilien en prend du coup pleinement possession. Transparence sur transparence, le verre et le liquide à l'intérieur laissent percevoir les formes de la main de la Madeleine, distendues par la courbe même du verre. Ce tour de force est comme une griffe si personnelle qu'il en devient un legs ${ }^{128}$. 
103 Par ce détail, Antonello fait bien plus que s'approprier pour sa plus grande gloire le génie des verriers de Murano. Il faut aller plus loin et voir dans la transparence de ce contenant la transparence de son contenu, l'huile. Nous avons déjà vu plus haut comment, de saint Bernard à Savonarole, l'huile de la pécheresse devient une offrande dévotionnelle. L'artiste, en se mettant à la place de la sainte, offre à son tour son huile à la Vierge, son humble outil d'artiste qui lui a permis de si bien la rendre, si présente, en toute luminosité. Bellini ne serait pas en reste de comprendre l'acte de peindre comme acte de dévotion.

Le retable de San Cassiano croise son chemin à un moment où il réfléchit longuement sur les possibilités qu'offre l'huile. Comment saurait-il arrêter ses réflexions à ses seules propriétés optiques? Peu habituelle encore dans les mains du peintre, l'huile garde pour lui sa forte prégnance d'associations dévotionnelles.

Ayant saisi les enjeux picturaux d'Antonello, il lui réplique. L'offrande d'huile demeure, mais éclot en toute une liturgie, une onction. Le vase dépouillé d'Antonello en est devenu somptueusement orné, comme si Bellini faisait montre de cet autre versant de la gloire des verriers de Venise, et de la maitrise qu'il en possède lui-même. L'artiste place le récipient en la possession du peintre Nicodème, celui qui a su faire une image qui outrepasse l'exercice de la mimesis, une image miraculeuse, en lui conférant une présence paroxystique. Pourtant, ce faste visuel du verre n'est que - comme la plaie de la main - suggéré, entr'aperçu, car Bellini le cache par les mains de Nicodème, comme pour montrer que l'important n'est pas le contenant mais le contenu qui se déverse de la plaie du côté129. Tel la Madeleine, cette figure du passage, aux parfums sacramentaux, il puise dans le vase, il y trouve les huiles pour créer cette icône à l'immanence exacerbée.

\section{Conclusion}

106 Avec la pala de Pesaro, un pas est franchi. La peinture à l'huile s'imposera bientôt comme l'art vénitien par excellence, qui lui confère les qualités de luminosité dans le coloris, la richesse dans la touche qui la caractérisent. Si Giovanni ici exploite ces vertus optiques intrinsèques à l'huile, il n'en exploite pas moins ses vertus théologiques. Dans la cimaise, le peintre vénitien confond le sujet représenté et la matière qui le représente. L'huile renvoie tautologiquement à elle-même. L'artiste outrepasse le comble de la mimesis - que l'huile parachève - pour fonder le sens même de son panneau. Autrement dit, la substance de l'huile donne à voir la scène de l'Onction, acte qui se fait en deux temps : par la Madeleine sur la plaie du Christ, et par la plaie du Christ sur le regard du spectateur. Aborder cette œuvre devient un rite sacramental.

Une méditation, si virtuose, si subtile, est rendue possible par la particularité de l'héritage vénitien, ses affinités avec l'icône, l'illusionnisme et le trompe-l'œil, et surtout, son attachement aux substances qui peuvent être en soi investies de signification. Elle suppose aussi une évolution du rôle de l'artiste. Le peintre fait apparaître la scène sacrée, tout en y participant. Par une métamorphose de cette huile, il oint le Christ et crée célébrant de ce mystère. comme le dirait Belting «Cela exige que le lecteur accepte l'idée d'une 
transformation fondamentale dans la conception et l'exécution d'une peinture [...] mais c'est au tableau même de Bellini à le prouver. ${ }^{130}$

108 Il convient, donc, de se pencher sur la génération suivante, en suivant les possibles leçons retenues de cette œuvre, notamment chez Titien, le plus brillant élève de Bellini. Cette substance devient, dans les mains de Titien, son titre de gloire et, par là-même, le sine qua non du «colorito alla veneziana». Bien entendu, à mesure que ce liant devient usuel, il perd de ses connotations sacrées, à plus forte raison quand ses qualités sont exploitées pour des nus féminins, si éloignés en esprit des Pietà du maître. Pourtant, c'est justement dans l'un de ses nus les plus célèbres qu'on repère l'indice le plus littéral d'une filiation avec l'Onction de Bellini, de la survie de sa pensée au travers d'une huile. Le sujet nous est connu : Marie-Madeleine (fig. 19). Dans la première version de 1530, comme dans celles qui suivent, la claire délectation dans le rendu de cette chair a mis en doute son contenu religieux.

Fig. 19

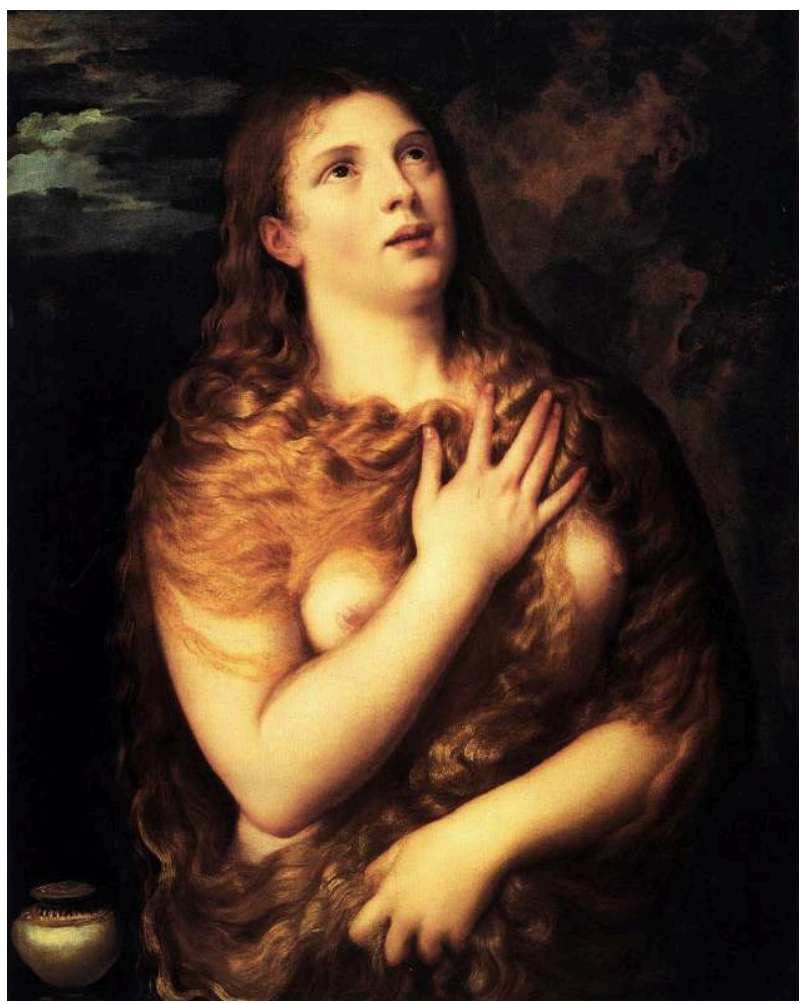

Titien, Madeleine pénitente, huile sur bois, 1530-1535, 84 × 69 cm, Florence, Palais Pitti

Sans entrer dans ce débat, remarquons seulement ceci : ce chantre du nu féminin, champion des valeurs esthétiques de son pays, doit ses moyens d'expression, son renom, à l'huile, et il indique leur source en laissant sa signature - à demi cachée par la margelle - comme gravée sur le vase de parfum. Tout au long de sa carrière, à l'évidence qui nous est parvenue, chaque fois qu'il se mettra à peindre une version de la myrrhophore, c'est auprès de cette huile que l'artiste laissera sa signature. Il montre déjà une sensibilité des enjeux symboliques de la signature et le médium dès sa maturité artistique, quand pour son Saint Sébastien il reprend une sculpture de MichelAnge, et exploite la ductilité de l'huile pour imiter un nom gravé dans le marbre (fig. $20)^{131}$. 
Fig. 20

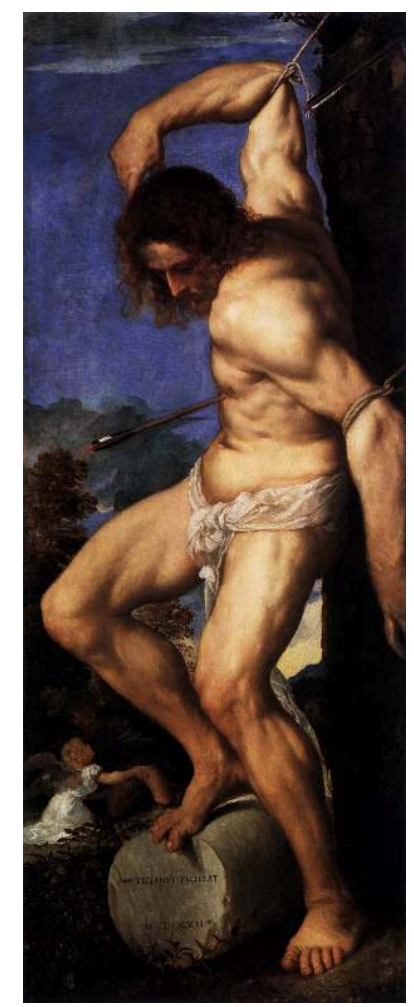

Titien, Retable de Brescia, détail : Saint Sébastien, 1520-1522, Brescia, Santi Naziano e Celso

110 Et à sa dernière période, poussant son travail de l'huile aux limites de ses propriétés picturales qu'il repartit avec ses mains ${ }^{132}$, il se présente dans la Mise au Tombeau en tant que l'un des Homme Saints (fig. 21) ${ }^{133}$, arrangeant le corps du Christ de telle sorte que les fluides de huile teinte de rouge s'écoulent sur ses doigts. 
Fig. 21

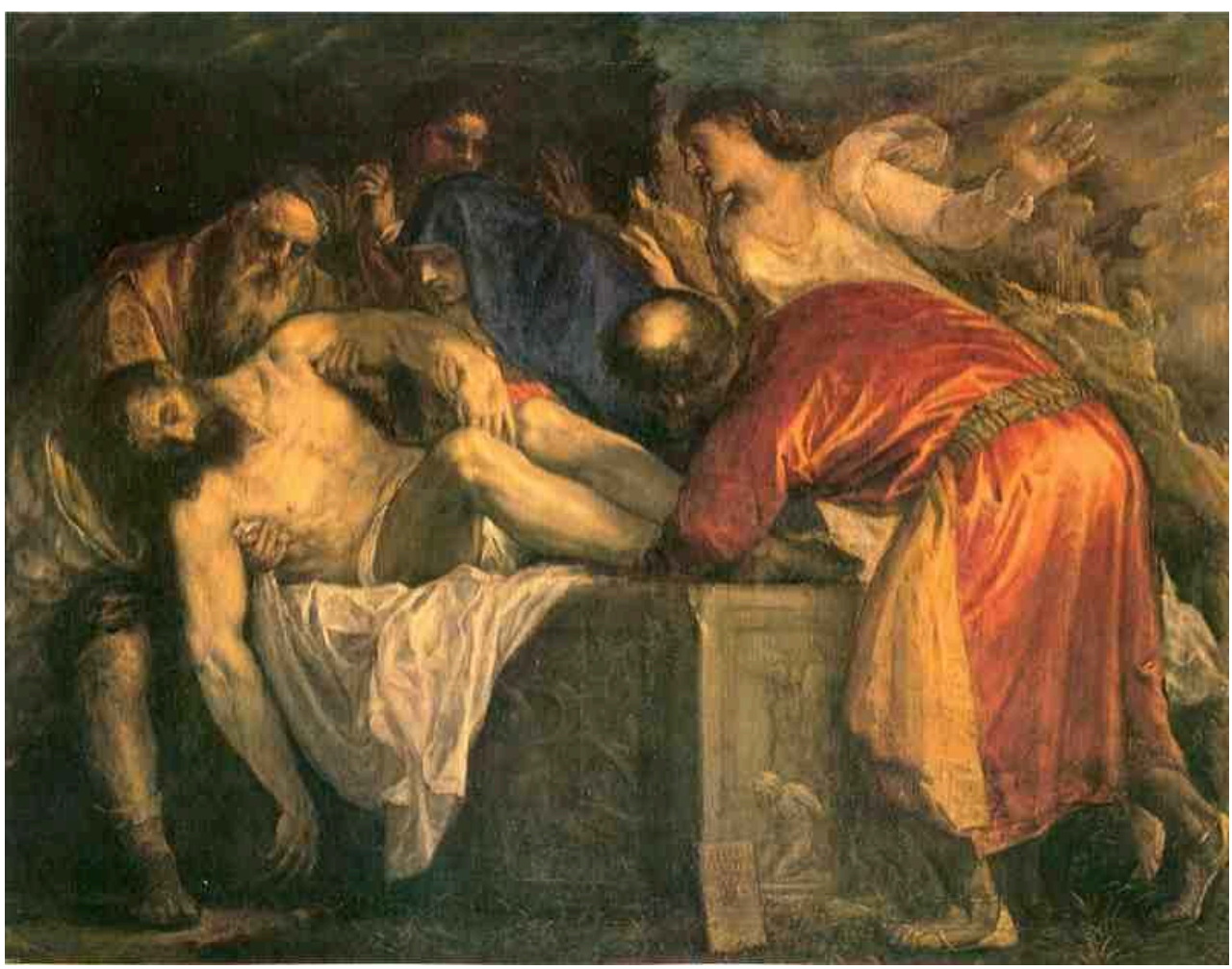

Titien, Mise au Tombeau, 1559, huile sur toile, $137 \times 175$ cm, Madrid, Musée du Prado

\section{NOTES}

1. Je tiens à remercier Jérôme Baschet et Thomas Golsenne dont les suggestions et critiques ont amélioré cet article. Les relectures de Véronique Dalmasso et Sylvain Piron ont également été précieuses.

2. Carolyn Wilson, Giovanni Bellini's Pesaro Altarpiece: Studies in its context and meaning, Ph.D., New York University, Institute of Fine Arts, 1976 ; Claudia Cieri Via, «A proposito della pala di Giovanni Bellini a Pesaro : considerazioni sulla simbologia del quadro d'altare", dans Arte d'Occidente : temi e metodi, studi in onore di Angiola Maria Romanini, a cura di Antonio Cadei, Rome, Sintesi Informazioni, 1999, t. 3, p. 1031-1047 ; Eugenio Battisti, « Riconstruendo la complessità », dans La Pala Ricostruita : L'Incoronazione della Vergine e la cimasa vaticana di Giovanni Bellini, Indagini e restauri, a cura di Maria Rosaria Valazzi, Venezia, Marseille, 1989, p. 6-14.

3. La restauration du Couronnement a donné lieu à un important colloque : La Pala Ricostruita, cité, et à la reconstitution temporaire de l'œuvre. Tous ces éléments ont été décisifs dans la confirmation du panneau du Vatican comme cimaise de la pala de Pesaro. Seules demeurent les réserves de Ileana Chiappini di Sorio, « Ancora sulla pala di Giovanni Bellini a Pesaro : precisione et ipotesi ", dans La Pala riconstruita, cité, p. 29-34. Des réponses à ses doutes sont apportées, dans ce même colloque, par les travaux très précis de Battisti, art. cit. , p. 14 ; Carla Bertorelli et Giovanna Martellotti, «Per una lettura critica dei dati tecnici », p. 85-88, et encore par Rona 
Goffen dans Giovanni Bellini, New Haven-Londres, Yale University Press, 1989, p.121-22 et 308, note 17.

4. L'on songe, par exemple, à celui de Paolo Veneziano, aujourd'hui à l'Accademia de Venise, ou celui de Gentile da Fabriano pour les Frères Mineurs de Valleromita aujourd'hui partagé entre la Brera de Milan et le musée Getty de Malibu. Pour un précis historique du thème, voir Wilson, op. cit. (note 2) p. 8-109.

5. Le premier exemple est probablement le retable de Bartolomeo Vivarini, aujourd'hui au musée de Capodimonte à Naples, datant de 1465. Voir Peter Humfrey, La Peinture de la Renaissance à Venise, New Haven-Londres, Yale University Press, 1995, trad. Catherine Fraixe, Paris, Adam Biro, 1996, p. 59. Au moins sous cette forme: Rona Goffen retrace l'origine de ce thème depuis les chapelles latérales d'Asisse. Voir « Nostra Conversatio in Caelis Est : Observations on the Sacra Conversazione in the Trecento ", Art Bulletin, 61, 1979, p. 198-222.

6. Voir Goffen, Giovanni Bellini, op. cit. (note 3), p. 122-33.

7. Pour l'évolution de la Pietà depuis l'Imago Pietatis, voir Hans Belting, L'Image et son public au Moyen Age, trad. Fortunato Israel, Paris, Gerard Monfort, 1998.

8. Rudolfo Palluchini parle de ce Compianto del Cristo qui « résout de façon toute neuve un thème cher à l'artiste» dans Giovanni Bellini, Milan, Martello, 1959 ; certains, comme Norbert Huse, Studien zur Giovanni Bellini, Berlin-New York, 1972 p. 29, Andreas Prater, « Mantegnas Cristo in Scurto ", Zeitschrift fur Kunstgeschichte, 48, 1985, p. 289, et Anchise Tempestini, « Giovanni Bellini et Marco Palmezzano ", Antichità Viva, 31, 1992, p. 5-12, ne se trompent pas en l'appellant Salbung Cristi, Embaumement du Christ. Wilson signale la particularité du motif et ses racines dans l'Imago Pietatis. Elle évoque l'Onction, mais, dans la lignée de Sixten Ringbom, semble trancher pour une Mise au Tombeau non narrative, op. cit. (note 2) p. 285-286. Le thème de l'Embaumement semble venir de l'Église orientale, importé vers l'Occident au douzième siècle. Il y a plusieurs exemples d'une onction du corps du Christ dans l'art français du treizième siècle. Au quinzième siècle le thème devient plus rare. Demeurent quelques exemples français : chez Jean Fouquet dans les Heures d'Étienne Chevalier (Chantilly), ou chez Jean Maraillet dans une œuvre à Nice. Pour l'art italien citons l'œuvre de Marco Palmezzano au Musée de Beaux-Arts de Dijon. Voir Engelbert Kirschbaum et. al., Lexicon der Christlichen Ikonographie, Fribourg, Herder, 1972, vol. 4 p. 11-14 ; Gertrud Schiller, Iconography of Christian Art, trans. Janet Seligman, Lund Humphries, Londres, New York, vol. 2, 1968, 1972, p. 172-173 ; et Louis Réau, Iconographie de l'art chrétien, Paris, P.U.F., 1957-58, tome II-2, p. 515-522. Remarquons au passage la Pietà de Tarrascon (Musée de Cluny) qui montre la Madeleine oignant le pied du Christ à l'aide d'un stylet ou d'un pinceau. Elle est datée de la première moitié du quinzième siècle.

9. Entre autre, cette pratique existait déjà dans la Lagune, notamment chez les verriers de Murano. Voir sur ce et plus largement sur l'usage de l'huile a Venise, Paul Hills, Il Colore veneziano : pittura, marmo, mosaico e vetro dal 1200 al 1550, New Haven-Londres, Yale University Press, 1999, trad. Alessandra Costa, Milan, Rizzoli, 1999, p. 71-81, 119 et 133 et Jill Dunkerton, « North and South in painting techniques ", in Renaissance Venice and the North, Londres, Thames and Hudson, 1999, p. 93-103. Il se peut que Giovanni ait voulu, pour ce thème aux sources orientales, suggérer par le melange un effet similaire au très ancien usage de la cire punique, que Venise connaitrait par le biais de ses comptoirs florissants en Tunisie. Voir Michelangelo Muraro, «Antonello : perché Venezia ", dans Antonello da Messina, atti del convegno (Messina 29 Nov-2 Dec. 1981), a cura di Alesandro Marabottini, Messine, 1987, p. 487 et note 13. Quoi qu'il en soit de cette hypothèse, Muraro nous explique que l'aspect brillant était de la plus haute importance dans la Sérénissime. Une ordonnance de la fin du treizième siècle interdit d'exporter toute œuvre qui n'aurait pas été préalablement vernie. De Venise aussi se diffusaient un peu partout des petits parchemins ou émaux recouverts de cristal. 
10. Goffen, op. cit. (note 3), p. 121-122 ; Humfrey, op. cit. (note 5), p. 71-72 ; et Alessandro Conti, «Giovanni Bellini fra Marco Zoppo e Antonello da Messina » dans Antonello, op. cit. (note 9), p. 290 , note 23.

11. Battisti, art. cit. (note 2), p. 14 ; Goffen, op. cit. (note 3), p. 121-122 ; Wilson, op. cit. (note 2), p. 447.

12. Voir Georges Didi-Huberman, «Un Sang d'images », Nouvelle revue de psychanalyse, $n^{\circ} 32$, 1985, où l'on trouvera l'idée du regard comme onction p.139 et, en sous-entendu, l'onction du regard.

13. Battisti, art. cit. (note 2), p. 6-7 ; Bertorelli et Martellotti, art. cit. (note 3), p. 87 ; et Chiappini di Sorio, art. cit. (note 3), p. 29-34. Palluchini, op. cit. (note 8), p. 52-53 ; Goffen, op. cit. (note 3), p. 308, n. 17 ; Wilson, op. cit. (note 2), p. 338-349 ; Conti, art. cit. (note 10), p. 292-295 ; Maddalena Trionfi Honorati, « Ipotesi di attribuzione della cornice della pala di Giovanni Bellini a Pesaro », Antichità Viva, 31, 1999, p. 40.

14. Palluchini fait le parallèle entre les deux oeuvres, op. cit. (note 8), p. 52 ; pour le retable (aujourd'hui entre Berlin et Pesaro) de Marco Zoppo daté de 1471, voir Conti, art. cit. (note 10), p. 277-285 ; Maria Rosaria Valazzi, «Pittori e pitture a Pesaro nel 400 », in Pesaro tra Medioevo e Rinascimento, Venise, 1990, p. 313-320 ; Patrizia Castelli « "Imago Potestatis" » : potere civile e religioso nella pala pesarese del Giambellino ", dans La Pala ricostuita, op. cit. (note 2), p. 18-21 et Wilson, op. cit. (note 2), p. 462 ; pour le retable de San Zeno, voir Humfrey, op. cit. (note 5), p. 52 -57 .

15. Bertorelli et Martellotti, art. cit. (note 3), p. 87.

16. Wilson, op. cit. (note 2), p. 153-154 et Battisti, art. cit. (note 2), p. 7-8.

17. Beaucoup de pages ont été consacrées à ce faux débat (voir, par exemple, Giulio Vaccaj, Pesaro, 1909; Everett Fahy, «New Evidence for dating Giovanni Bellini's Coronation of the Virgin ", Art Bulletin, 46, 1964, p. 216-218 ; et Palluchini, op. cit. Encore, très récemment, on a proclamé sans ambages que le retable est une commande des Sforza, sur ce seul raisonnement. Grazia Calegari, «La pala di Pesaro e la città in quegli anni ", dans Adriatico : un mare di storia, arte, cultura, Atti del convegno 20-22 maggio 1999, a cura di Cleri Bonito, Ripatronsone, Ancona, Maroni, 2000, vol. II, p. 129-138. Outre le fait que cette identification architecturale a été amplement démentie - par exemple voir Wilson, op. cit. (note 2), p.171-177 - une telle lecture reste insatisfaisante eu égard à la compréhension de la logique interne du tableau.

18. Ibid., p. 184-209, Battisti art. cit. (note 2), p. 9, et Goffen, op. cit. p. 133.

19. Ead., p. 123-125.

20. Belting, op. cit. (note 7), p. 99-140 ; R. Goffen, Piety and Patronage in Renaissance Venice, New Haven-Londres, Yale University Press, 1986, p. 52-54 ; Ead., «Icon and Vision: Giovanni Bellini's Half-Length Madonna ", Art Bulletin , 57, 1975, p. 487-518.

21. Goffen, Giovanni Bellini, op. cit. (note 3), p. 125 signale cette solution, et Palluchini, op. cit.. (note 8), p. 54 en signale l'originalité.

22. Goffen, ibid. p. 125-128, Wilson, op. cit.. (note 2), p. 415-418 et Palluchini, ibid. (note 8), p. 54-57. 23. Dès le quinzième siècle, le verre vénitien dépasse le travail des verriers orientaux par la finesse de ses effets de transparence et ses formes délicates. Le rosechiero en était un exemple. Ce verre légèrement teint de pourpre s'obtenait en appliquant une couche de manganèse - à la manière de l'émail - sur la surface du verre. Le résultat était si fragile qu'aucun exemplaire ne nous est parvenu. Peu commun avant le tournant du siècle, la technique fut mise au point dans le dernier quart du Quattrocento. Voir Hills, op. cit. (note 9), p. 126 et note 30. Son perfectionnement date donc des mêmes années que notre panneau. La rareté de ce verre, sa préciosité, seraient sans doute des qualités tentantes pour figurer la fiole d'onguents pour un artiste sensible aux inventions de Murano, comme l'était Bellini.

24. Le thème de l'onction étant rare, il faut chercher les points de comparaisons dans les représentations du vase de Marie-Madeleine. Celui-ci est figuré, dans l'art italien, généralement 
de deux manières : en vase de pierre blanche ou marbré, d'après le vase d'albâtre des Évangiles, ou bien en pièce d'orfèvrerie, comme pour rappeler un reliquaire.

25. Voir la Déposition de Giottino aux Offices datant autour de 1360 ou la Lamentation de Fra Angelico commandée par Fra Sebastiano Benintendi en 1436 au musée San Marco à Florence.

26. Les raisonnements - circonstantiels, mais convaincants - se poursuivent chez Goffen, Giovanni Bellini, op. cit. (note 3), p. 309, note 13 ; Wilson, op. cit. (note 2), p. 155 et 383-387 ; et Battisti, art. cit. (note 2), p. 8-9. Sa taille seule aurait nécessite un lieu dégagé. Anchise Tempestini, Giovanni Bellini : Catalogo completo, Florence, I Gigli dell'arte, 1992, p. 82, affirme que cette œuvre est la plus grande de sa maturité qui nous soit parvenue. Les panneaux seuls ont les dimensions suivantes : Couronnement $262 \times 240 \mathrm{~cm}$; cimaise $107 \times 84 \mathrm{~cm}$, scènes de prédelle $40 \times 42 \mathrm{~cm}$. Sans compter le série de corniches, le retable mesure plus de quatre mètres de haut : il aurait étouffé tout œuvre environnante. Le polyptique de Iacobello, autre œuvre essentielle à la dévotion dans cette église, ne mesure que 129 × $245 \mathrm{~cm}$ selon Jaques Dalarun, La Sainte et la cité : Micheline da Pesaro, tertiaire franciscaine, Rome, CEFR, 1992, p. 108, note 26. De plus, cette ville de province est dominée par Venise ; la Madone Rucellai, deux siècles plus tôt, offre un exemple d'une œuvre de grande dimension placée dans une chapelle de confrérie. Toute en gardant cela à l'esprit, il est difficile d'imaginer que des fonds et de l'énergie aient été dépensés pour se procurer une œuvre de taille exceptionnelle d'un des meilleurs peintres de la Sérénissime, pour la mettre ailleurs que sur l'autel principal.

27. Wilson, op. cit. (note 2), p. 112.

28. Dalarun, op. cit. (note 26), p. 146.

29. On se souviendra, par exemple, de la présence de Gentile Bellini à la cour de Mohamet II. Pour les informations sur Pesaro, les Malatesta et les Sforza, voir les différents travaux dans Pesaro tra Medioevo e Rinascimento, op. cit. (note 14) ; Castelli, «Imago", art. cit. (note 14), p. 15-28 ; Ead., «Cronache dei loro tempi II », dans Pesaro, op. cit. p. 223-254; Vaccaj, op. cit. (note 17) et Dalarun, op. cit. (note 26)

30. Malgré le culte local qui la reconnaît comme sainte, Michelina ne sera en fait jamais canonisée, mais béatifiée. Voir Dalarun, ibid., p. 11-12.

31. La reconstitution de San Francesco bute contre le manque d'archives. Voir toutefois Luigi Michelini Tocci, Pittore del 400 ad Urbino ed a Pesaro, Pesaro, Cassa di Rispiarmo, 1840-1914, p. 50-56 ; Wilson, op. cit. (note 2), p. 155 et 383-387 ; Goffen, Giovanni Bellini, op. cit. (note 3), p. 308, n. 13 et Dalarun, ibid., p. 71, 76, 108.

32. Dalarun., ibid., p. 121-6.

33. Id., ibid., p. 140. Le texte est malheureusement inédit.

34. Conti, art. cit. (note 10) p. 277 et suivantes. Le panneau principal est au jourd'hui au Bodesmuseum de Berlin. Sa cimaise est restée à Pesaro, actuellement dans le Museo Civico.

35. Valazzi, art. cit. (note 14), p. 320. Ceci n'est peut-être pas anodin dans une église conventuelle.

36. Antonio Carile, « Pesaro nel medioevo », dans Pesaro, op. cit. (note 14), p. 318.

37. Valazzi, ibid., p. 321-327 et Castelli, Imago, art. cit. (note 14), pp. 16-24 présentent des arguments en faveur d'une commande des Sforza. Beaucoup plus réservée sur ce point sont Wilson, Palluchini et Goffen. Voir par exemple pour cette dernière, Giovanni Bellini, op. cit. (note 3), p. 137 et n. 30, p. 309.

38. Voir John Fleming, From Bonaventure to Bellini. An Essay in Franciscan Exegesis, Princeton, 1982, et Goffen, Piety, op. cit. (note 20), p. 54.

39. Pour ce « byzantine revival », voir Hills, op. cit. (note 9), p. 157 ; Goffen, Piety, op. cit. (note 20), p. 51; et Élizabeth Crouzet-Pavan, "Récits, images et mythes : Venise dans l' "iter" hiérosolomytain ", Mélanges de l'École Française de Rome, t. 96, 1984-1; et Hans Belting, Image et Culte, trad. F. Muller, Paris, Cerf, 1990, p. 461-462.

40. Pour le fonctionnement des icônes et leur relation intime avec les reliques, voir Belting, ibid.

41. Id., L'Image et son public, op. cit. (note 7), p. 35-44 et 78-79. 
42. Pour la légende du crucifix de Beyrouth, Id., Image et Culte, op. cit. (note 39), p. 412-413; JeanPierre Albert, Odeurs de Sainteté, Paris, Éd. de l'EHESS, 1990, 1996, p. 226-230 et 345 ; Jacques de Voragine, Légende Dorée, trad. J.-B. M. Roze, Paris, Flammarion, 1967, vol. II, p.196.

43. Id. p. 266.

44. Retable de Santa Elena, Accademia, Venise.

45. Transféré à l'Église de Santa Lucia, puis au Nuovo Polo Museale di San Francesco, à Montefiore dell'Aso.

46. Pinacoteca Vaticana.

47. Dalarun, op. cit. (note 26), p. 108, n. 26-27, remarque le parenté de techniques, aussi bien que son aspect exceptionnel. Il est vrai qu'en 1443 dans le Polyptique de la Vierge dans l'église de San Zaccaria, Vivarini et Giovanni d'Alemagna utilisent le mélange de dimensions, mais les sculptures sont sur les marges du retable, et non pas au milieu.

48. Rijksmuseum, Amsterdam (réserves). En ce qui concerne les circonstances de sa commande, voir Marilena Mosco, «L'Iconografia della Maddalena nella pittura di Carlo Crivelli dalla Pala di Montefiore a quella di Fabriano ", dans Il Patrimonio disperso : il "caso" esemplare di Carlo Crivelli, Actes du colloque, Montefiore dell'Aso, Camerino, Porto San Giorgio, 12, 26 oct., et 9 nov., a cura di Marina Massa, Regione Marche, Assessorato alla Cultura Centro Beni Culturale, Maroni, 1999, p. 83-112.

49. Pour la Pala de San Giobbe et le Triptyque des Frari, voir Goffen, Piety, op. cit. (note 20), p. 39-54 ; pour le retable de Sainte Catherine de Sienne, ead., Giovanni Bellini, op. cit. (note 3), p.119 et Humfrey, op. cit. (note 5), p. 67 ; pour le retable de San Zaccaria, voir Tempestini, op. cit. (note 26), p. 252.

50. Pour les aspects iconiques des Madones et des Pietà, voir Goffen, «Icon and Vision », art. cit. (note 20), p. 509-514 ; Belting, Giovanni Bellini. La Pietà, trad. Marco Pedrazzi, Modène, Franco Cosimo Panini, 1985, 1986, p. 20-29 ; Id., Image et Culte, op. cit. (note 39), p. 461-463.

51. Détail relevé par Hills, op. cit. (note 9), p. 114-120, qui fait état de la perméabilité des milieux des fiolarii et des peintres de tableaux. Alvise Vivarini, père d'Antonio et Bartolomeo était luimême verrier de Murano.

52. Il s'agit du traité Reductorium Morale du bénédictin Pierre Bersuire, voué à une longévité certaine puisqu'il sera publié à Venise en 1585. Voir Erwin Panofsky, Les Primitifs flamands, trad. Dominique Le Bourg, Paris, Hazan 1992 (éd. orig. Harvard, 1971), p. 280-281 et note 13. (Cette remarque est relevée par Muraro, art. cit. p. 480, note 5, qui ouvre par ailleurs d'autres pistes pour la sacralité de la peinture à huile). Bonaventure explique que les sacrements peuvent être administrés dans certains cas en dehors du sacerdoce: Breviloquium, partie 6, Les Remèdes Sacramentels, texte latin et traduction Luc Mathieu OFM, Paris, Éditions Franciscaines, 1967, p. 66-75.

53. Matt. 26, 7-13, Marc 14, 1-9.

54. Luc 7, 37-50.

55. Jean 11, 1-46.

56. Luc $10,38-42$.

57. Jean 12, 1-8.

58. Albert, Odeurs, op. cit. (note 42), p. 173-174. Tout ce chapître est voué à une discussion des interrelations entre Christ, l'onguent et Marie-Madeleine. Voir aussi Didi-Huberman, art. cit. (note 12).

59. Fleming, op. cit. (note 38), p. 161-163, et Goffen, Piety, op. cit. (note 20), p. 54.

60. «Propter quod dicuntur omnia sacramenta habere eficaciam a passionne Christi. Unde secundum Augustinum "de latere Christi dormientus fluxerunt sacramenta" dum ine fluxit sangis et acqua "in medio plateae eius" id est Ecclesia quae est corpus mysticum ut per eum vivificetur »: Bonaventure, Sermones Dominicales, sous la direction de Jacques-Guy Bougerol, OFM, Quaracchi, Sermo 4, Dominica Tertia Adventus, v. 6 p. 159. La même pensée se profile derrière 
une légende racontant qu'Adam, mourant, ne pouvait guérir que par l'huile de l'arbre de vie, c'est-à-dire, le sang du Christ sur la croix. Voir Jacques de Voragine, op. cit. (note 42), vol. I, p. 341-343.

61. Dictionnaire d'Archéologie Chrétienne, sous la direction de Fernand Cabrol et Henri Leclercq, Paris, Letouzey, 1925, article de Cabrol, « Huile», vol 6, $2^{\mathrm{e}}$ partie, col. 2778-2791; pour les croix ointes, et oignantes, et pour la récupération des effluves de reliques, voir aussi Albert, op. cit. (note 42), p. 170-171; pour d'autres discussions sur les huiles, les odeurs et le reliques, voir André Vauchez, La Saintété en Occident aux derniers siècles du moyen âge, Rome, École Française de Rome, 1988, p. 499-518 ; Belting, Image et Culte, op. cit. (note 39), p. 87-88.

62. Goffen, Piety, op. cit. (note 20), p. 42, 54.

63. "Oleum effusum nomen tuum. » Bernard de Clairvaux, Sermons sur le Cantique, texte latin de Jean Leclerq, Henri Rochas et Charles H. Talbot, Paris, Cerf 1996, La phrase est un leitmotif, voir par exemple t.1, Sermon 15, II, p. 330-337.

64. «Hoc tibi electuarium habes $O$ anima mea reconditum in vasculo vocabuli huius quod est Iesus » : Id., ibid., Sermo 15, IV, 7, p. 342-343.

65. Id., ibid., Sermo 15, III, 5, p. 336-337 : «Est procul dubio inter oleum et nomen sponsi similitudo [...] fovet ignem [...] lenit dolorem [...] Lux [...] medicina. »

66. «Est ergo unguentum, quod sibi coficit anima multis irretta criminibus, si cum incipit cogitare vias suas colligat congerat sonteratque in mortariolo conscientiae multas varias species peccatorum suoorum, et intra aestuantis pectoris ollam simul omnia coquot igne quodam paententiae et doloris »: Id., ibid., Sermo 10, IV, 5, p. 222-224. Ce trope aura toujours cours à travers les siècles et se retrouve dans les derniers écrits de Savonarole: "Marie-Madeleine composa un tel onguent, elle le déposa dans le vase de son cœur [...]». Voir Savonarole, Miserere, tr. Charles Journet, Paris, Desclée de Brouwer, 1968, 1994, p. 99.

67. «In calore Spiritus Christo Domini, cui confricatur, inhaerens, stillante ac fundente undique sui oleum exsultionis, prae participibus qus excipiens ipsum, ai t: oeum effusum noment tuum, Quid mirum si ungitur, quae unctum complectitur », Id. Ibid., Sermo 14, II, 4, p. 314-315.

68. Le thème est récurrent. Voir par exemple Id., ibid., Sermo 3, I, 2, p. 104-105, et12, IV, 6 p. 266-267.

69. "Unde sequitur"infundens oleum" id est charisma spiritus sancti», dans Sermones Dominicales, op. cit. (note 60), Domenica XII post pentecoste, v. 12, p .404.

70. Lexique de Saint Bonaventure sous la direction de Jacques-Guy Bougerol, OFM, Paris, Éditions Franciscaines, 1969. Voir les rubriques « Devotio », p. 53 et « Unctio », p. 129.

71. «Mitte oleum in omnia vasa. Per oleum significatur devotion mentis », dans Zafirana, op. cit. (note 69), p. 117.

72. Bonaventure, op. cit. (note 52), p. 44-45.

73. Augustin, Homilies on the Gospel of John ; Homilies on the First Epistle of John; Soliloquies, ed. Philip Schaff, New York, Christian Literature Publishing Co., 1886, tractate XII, 3-5. Bernard de Clairvaux, Lettres, tr. H. Rochas, Paris, Cerf, 2001, tome II, p. 322-323 et XV, 5.

74. Les Synoptiques parlent seulement de Joseph : Matt. 27, 57-60 ; Marc 15, 43-46 ; Lc 23, 50-54. Seul Jean mentionne Nicodème : $3,1-21 ; 7,50-52 ; 19,38-42$. Ce personnage laissera son nom à un évangile apocryphe connu aussi comme Acta Pilati qui sera d'ailleurs source des légendes du Graal avec Joseph. Voir The Apocryphal New Testament, tr. J. K. Elliott, Oxford, Clarendon Press, 1993, p. 161-225. Pour la légende du crucifix de Beyrouth, voir supra, note 42. En Français voir Écrits apocryphes chrétiens, tome 2, sous la direction de Pierre Geoltrain et Jean-Daniel Kaestli, Paris, Gallimard Pleiade, 2005, p. 249-297.

75. Les passages évangéliques qui serviront à créer le personnage sont les suivants : Matthieu 26, $1-23$; 27, 54-61; 28, 1-10 ; Marc 14, 3-9; 15, 40-41 et 47 ; 16, 1-8 et 9-11; Luc 7, 36-50 ; 8, 1-3 ; 10 , 
$38-42 ; 23,55-56 ; 24,1-11$; Jean $11,2-43 ; 12,1-11 ; 19,25 ; 20,1-18$. Pour la mis en place du personnage voir par exemple Élisabeth Pinto-Mathieu, Marie Madeleine dans la littérature du Moyen Âge, Paris, Beauchesne, 1997, p. 3-11.

76. Albert, Odeurs, op. cit. (note 42), p. 174-5 et 213-222 l'exprime avec éloquence : « le personnage de Marie Madeleine ne s'articule-t-il pas tout entier [...] sur une pensée de parfums ?» Piroska Nagy, Le Don des larmes au moyen âge, Paris, Albin Michel, 2000, p. 257-267, pousse l'analyse encore plus loin. Pour elle, il s'agit d'une figure de fluides, sur le flux et reflux d'une grâce toute liquide ; pour d'autres réflexions sur ces idées voir aussi Didi-Huberman, art. cit. (note 12), p. 124-128 ; Pinto-Matthieu, op. cit. (note 76), p. 24-59.

77. Albert, ibid., p. 144.

78. La mise en place de nombre de ces tropes est analysée par Dominique Iogna-Prat dans «La Madeleine du Sermo in veneratione Sanctae Mariae Magdalenae attribué à Odon de Cluny » dans La Madeleine, Mélanges de l'École Française de Rome, t. 104, 1992-1, p. 37-70. L'appellation Illuminatailluminatrix se trouve, par exemple, chez Jacques de Voragine, op. cit. (note 42), p. 456.

79. Bernard, op. cit. Note 75, Sermo 10, IV, 6-7, p. 224-227: « [...] illo visibili, quo visbiliter uncti a peccatrice corporei Dei referentur in Evangelio [...] peccatricis manibus distillabatur, et extremis membris corporis [...] ecurae manus vestrae distillent myrrhae amaritudinem in salubrem hanc unctionem, quia cor contritum et humiliatum Deus non despeciet. "

80. Zelina Zafarana, "Pietà e devozione in San Bonaventura" in Da Gregorio VII a Bernardino da Siena, a cura di Ovidio Capitani, Claudio Leonardi, Enrico Menestò e Roberto Rusconi (1e ed. 1987), Spoleto, CISSAM, 1991, p. 12 et n. 2.

81. André Vauchez, La spiritualité dans le Moyen Age Occidental, Paris, Seuil, 1994, p. 158-168.

82. Dalarun, op. cit. (note 26), p. 44-75, et 121-145 pour le recoupements entre ces figures et les pratiques rituelles autour de Michelina.

83. Dictionnaire d'Archéologie Chrétienne, art. cit. (note 61), col. 2779-2782.

84. Dalarun, op. cit. (note 26), p. 71-76.

85. Goffen, Giovanni Bellini, op. cit. (note 3), p. 308, n. 12.

86. Battisti, art. cit. (note 2), p. 7-9. Pour Cieri Via, art. cit. (note 2), p. 1031-1035, il s'agit d'une référence à un templum, voire une iconostase.

87. Cette analyse se trouve chez Wilson, op. cit. (note 2), p. 153-155. Le procédé annonce le travail de Titien qui incorpore mobilier liturgique et éléments architecturaux des Frari pour le programme de son Assunta, d'après l'analyse de Rosand, reprise par Goffen, Piety, op. cit. (note 20), p. 97 et par Wilson, op. cit. (note 2), p. 389.

88. Expression de Palluchini, op. cit. (note 8), p. 53.

89. Il est intéressant d'appliquer à notre propos ces paroles de Hills, op. cit., (note 9), p. 138-140 à l'égard de la Pala Barbarigo.

90. Bonaventure, Arbre de Vie / Lignum Vitae, trad. Jacques-Guy Bougerol OFM, Paris, Éditions Franciscaines, 1996, p. 85 et Lexique, op. cit., rubriques «Illuminatio », p. 84 et « Medium », p. 97. Voir aussi de Bonaventure, Sermones Dominicales, op. cit., (note 60), Dom. Tertia Adventus Sermo 4, v. 6, p. 159.

91. Belting fait état de la pratique byzantine de dorer les mains des intercesseurs, ce par quoi ils prient, donc agissent: Image et Culte, op. cit. (note 39), p. 58-60. Plus proche de notre retable, Gentile de Fabriano dans sa Présentation au Temple au Louvre, autrefois appartenant à la prédelle de L'Adoration des Mages aux Offices, figure la flamme de la lampe à huile du sanctuaire avec la feuille d'or.

92. Pour Hills, op. cit. (note 9), p. 155-156, on peut comprendre l'huile comme un baume qui lie le continuum optique.

93. Alexandre Perrig, "La Peinture et la sculpture du bas Moyen Âge » dans La Renaissance Italienne : Architecture, Sculpture, Peinture, et Dessin, sous la direction de Rolf Toman, Köln, Paris, La Martinière, 1995, p. 37-40. 
94. Belting, L'Image et son public, op. cit. (note 7), p. 200-20.

95. Ces paragraphes suivent de près l'article de Daniel Russo, « Saint François, les Franciscains et les représentations du Christ sur la croix en ombrie au XIII ${ }^{\mathrm{e}}$ siècle », MEFRM, 96 (1984), n 2, p. 647-717. Ces idées sont réélaborées par Didi-Huberman, art. cit. (note 12).

96. Russo, ibid., p. 650.

97. Arbre de Vie, op. cit. (note 90), p. 64-65.

98. Belting, La Pietà, op. cit. (note 50). Pour les échanges avec Mantegna, voir en particulier p. 22-27 et 38-45. Pour ceux avec Antonello, p. 53-62.

99. Id., ibid., p. 54.

100. Id., ibid., p. 13.

101. Pour la Pietà de Brera, je reproduis l'analyse de Belting, La Pietà, op. cit. (note 50), avec les precisions de Daniel Arasse, "Giovanni Bellini et les limites de la mimesis : la Pietà de Brera ", dans Künstlerische Austausch/Artistic Exchange, Akten des XXVIII Internationalen Kongresses für Kunstgeschichte Berlin 15-20 Juillet, 1992, Akademie Verlag, p. 503-509.

102. L'appelation vient de Belting, ibid., p. 20.

103. Les traductions du latin, aussi bien que leur relation exégétique avec l'image, sont de Daniel Arasse, art. cit. (note 101).

104. Tout comme Properce, du reste.

105. Leon Battista Alberti, La peinture, traduction française de Thomas Golsenne et Bertrand Prévost, revue par Yves Hersant, Paris, Seuil, 2004, p. 97.

106. D'aucuns parlent d'une œuvre en biscuit, d'autres du bois sculpté comme le réclamait la ville de Lucques à l'égard de la relique que conservait sa cathédrale. Encore d'autres parlent d'un tableau. En tout état de cause, que le support soit en deux ou en trois dimensions, il aurait été toujours question de l'usage de pigment et liant. Même le crucifix de Lucques - malgré le témoignage (non-oculaire) de Matthias Janov à la fin du quatorzième siècle - devait être, dès l'origine, peinte. Voir Belting, L'Image et son public, op. cit. (note 7), p. 21; id., Image et Culte, op. cit. (note 39), p. 412-413 et 730-731; Jacques de Voragine, op. cit. (note 42).

107. D'autres artistes cèderont aussi à la tentation de donner ses traits au saint-artiste, par exemple Michel-Ange dans sa Pietà du Vatican. Pour une discussion de ce choix qui inclut les Pietà de Giovanni Bellini, voir Goffen, Renaissance Rivals, New Haven-Londres, Yale University Press, 2002, p. 372-376. L'on peut également consulter Jane Kristof, « Michelangelo as Nicodemus : The Florence Pietà ", The Sixteenth Century Journal, Vol. 20, n 2, Summer 1989, p. 163-182, qui donne des exemples d'autoportraits d'artistes en tant que Nicodème en Italie aux Quattrocento et Cinquecento, surtout p. 170.

108. Les empreintes digitales, si exceptionnelles pour la période et surtout pour l'artiste, sont fort suggestives pour notre propos. Voir Battisti, art. cit. (note 2), p. 11 ; Bertorelli et Martellotti, art. cit. (note 3), p. 92 et n. 39.

109. Voir Gioia Mori, «"Quarto fuit sanguinisa deitate" : la disputa di S. Giacomo della Maro nel Polittico di Massa Fermana di Carlo Crivelli », Storia dell'arte, n. 47, 1983, p. 17-27 et DidiHuberman, art. cit. (note 12) p. 142-147.

110. Les Annunziata d'Antonello se construisent aussi sur l'idée de projeter le spectateur dans un face-à-face participatoire dans un événement fondateur du christianisme.

111. Révérée à Constantinople, après avoir été amenée de Jérusalem à Éphèse par MarieMadeleine. L'intérêt de cette relique recoupe avec une autre venue de la capitale orientale : du parfum de Marie-Madeleine mélangée avec une goutte du sang christique, gardé aux Frari de Venise depuis 1479. Dans les deux cas il s'agit des mêmes protagonistes et le même thème de l'onction et des humeurs du christ. Pour la pierre, voir Prater, art. cit. (note 8), p. 285-292 ; Mori, art. cit. , (note 109), p. 17-27 ; pour le vase, voir Goffen, Piety, op. cit. (note 20), p. 21 et n. 67, 75 et 79 p. 176-177. 
112. Pourtant, dans cette œuvre qui joue - de par la hardiesse de son raccourci - sur la distance pour suggérer la proximité, il n'est pas question du toucher. On ne voit pas l'acte même d'oindre. Il est à se demander si il ne se joue pas ici justement deux préoccupations différentes une propre à l'huile et l'autre au tempera. Je remercie Thomas Golsenne pour cette observation.

113. C'est Daniel Arasse qui y voit un autoportrait; voir Le Détail : Pour une histoire rapprochée de la peinture, Paris, Champs-Flammarion, 1996, p. 88.

114. Sur les différentes versions de l'Ecce Homo, voir Gioacchino Barbera, Antonello da Messina, trad. Francoise Liffran, Milan, Electa, et Paris, Gallimard, 1998, p. 40-48, 137, et 147-151; Antonello Da Messina, Catalogo della Mostra, a cura di Alessandro Marabottini e Fiorella Sricchia Santoro, Roma, ed. De Luca, 1981, p. 81-82.

115. Musée du Louvre.

116. La sueur du sang apparaît dans Luc 22, 44. Sur la permutation des humeurs christiques, voir Nagy, op. cit. (note 75), p. 306.

117. Pour l'histoire de la Véronique, voir Belting, Image et Culte, op. cit. (note 39), p. 277-300. Pour L'Évangile de Nicodème, ch. 7, dans Elliott, op. cit. (note 76), p. 175, n. 13, Véronique est l'hémoroïsse guérie en touchant le Christ : Apocryphi Hypomnemata Domini Nostri seu Acta Pilati. Studia Syriaca, fasc. II, 1908. Ed. Ignatius Ephraem Rahmani p.18. Pour Jacques de Voragine, l'hémorïsse est Marthe, donc sœur de Marie-Madeleine telle qu'elle est construite : op. cit. (note 42), vol. I, p. 457 ; vol. II, p. 22-23. Nous demeurons dans une réflexion de sanies et les miracles qui les entourent.

118. Kunstorischesmuseum, Vienne.

119. Voir Lionello Puppi, «I committenti veneziani di Antonello : appunti a margine di qualche identificare » dans Antonello, op. cit. (note 9), p. 223-225.

120. Tempestini, op. cit. (note 26), 1997, p.64.

121. Goffen, Giovanni Bellini, op. cit. (note 3), p. 119-122 et Humfrey, op. cit. (note 5), p. 71-76.

122. Ead., ibid., p. 122.

123. André Chastel, La Pala ou le retable italien des origines à 1500, Liana Levi, Paris, 1993. p. 24.

124. Ce détail fut révélé après un nettoyage au début du siècle ; voir Antonello, cat., op. cit., (note 114), p. 176.

125. Le vase de la Madeleine de Piero della Francesca, déjà signalé, n'est peut-être pas pour rien dans ce contexte. Ces objets pourraient fournir d'éventuelles pistes concernant le contact entre les artistes en question. Ceci est malheureusement hors du propos de l'étude présente.

126. Paul Hills, "Venetian glass and Renaissance self-fashioning" in Concepts of Beauty in Renaissance Art, ed. Francis Ames-Lewis et Mary Rogers, Ashgate, Aldershot 1998, pp. 163-178.

127. Jacqueline de Pasquier, Histoire du Verre, Paris, Massin, 2005, p. 148.

128. Dans le Theatrum Pictorium de Teniers paru en 1684 on tente de reproduire l'œuvre en gravure, de réussir le raccourci de la main de Saint Nicolas, et sa crosse si finement ouvragée, elle aussi en transparence. Quant aux mains de la Madeleine, elles sont cachées dans son manteau. Le détail fut-il à cette époque déjà recouvert, ou le graveur renonce-t-il à cette hardiesse ? Il a été également suggéré que le détail fut un rajout pour rendre le panneau " plus autonome " après son démembrement (voir Antonello, cat., op. cit., (note 114), p. 81-82 et p. 176). Mais il est difficile de voir dans ce morceau magistral une tentative ultérieure de rattrapage. C'est bel et bien la main d'Antonello à l'œuvre. En outre, quand son fils exécute sa première œuvre après la mort de son père en 1479 -qui est peut-être une continuation ou une reproduction d'une œuvre du père, il « cite » le verre transparent. Voir la Vierge aux Cerises de Bergame, Accademia Carrara, Ibid., p. 202.

129. L'on songe encore au paradoxe significatif de saint François dans la Pala de San Giobbe: le poverello offre sa plaie au toucher contemplatif, tout en le cachant de la vision - avec son doigt. 130. Belting, La Pietà, op. cit. (note 50), p. 30. 
131. Pour les enjeux du parangon entre la mimésis corporelle de Saint Sebastien repris de l'Esclave Mourant de Michel Ange, voir Goffen, Renaissance Rivals , op. cit. (note 107) pp. 290-293.

132. «Pour les dernières touches il estompait les transitions entre les lumières et les demiteintes avec ses doigts...ou alors il appliquait du bout du doigt ... une pointe de rouge, telle une goutte de sang...Dans les derniers stades, il peignait davantage avec ses doigts qu'avec le pinceau. » Boschini, cité par David Rosand, La Trace de l'artiste : Leonard et Titien, traduit par Jean Bouniort, University of Kansas 1988, et Paris, Gallimard, 1993 p. 118.

133. Museo del Prado, Madrid. L'autoportrait est remarqué, par exemple, dans Titian Prince of Painters, Catalogue de l'expostion, Venise, 2 juin-7 octobre 1990 et Washington D. C., 28 octobre 27 janvier 1991, éd. Susanna Biadene, Venise, Marsilio Editori et Prestel 1990, cat. n 70, p. 354.

\section{RÉSUMÉS}

Cet article aborde spécifiquement et en profondeur la cimaise du Couronnement de la Vierge toujours conservé à Pesaro duquel elle a été détachée. Nous nous penchons particulièrement sur l'iconographie particulière du panneau qui peut mieux être qualifié de scène d'Onction. Nous nous posons pour but de comprendre le lien entre le choix de sujet de Giovanni Bellini et son choix de pousser plus loin son adoption de l'huile comme médium pour ses vertus propres. Nous pourrons ainsi comprendre sous un autre angle le développement de l'avènement de la peinture à l'huile dans l'art vénitien où le médium serait investi de signification symbolique. L'huile comme liant serait en relation tautologique, au sens russoien, avec la scène représentée. L'argument se développe selon trois axes : les traditions plastiques de l'ordre franciscain, la production de la culture visuelle de Venise, et la "conversation" beltingienne entre le Vénitien, Andrea Mantegna et Antonello da Messina. En examinant bien les pièces du dossier, il semble que Giovanni Bellini veuille peindre sa propre image miraculeuse qui prépare un rite sacramentel de contemplation dans lequel l'artiste serait le sacerdoce.

This article addresses specifically and in depth the cornice panel of the Crowning of the Virgin still kept in Pesaro from which it was separated. We look at its particular iconography that could better be qualified as a scene of an Unction of Christ. Our goal is to understand Giovanni Bellini's choice of subject matter as well as his choice of pushing further here his experimentation of oil as binding for its own inherent properties. We can thus understand the advent of Venetian oil painting through another angle in which the medium would be invested with symbolic meaning. The oil as binding would be in a tautological - in Daniel Russo's sense of the word- relationship with the painted subject. The argument is developed along three main paths : that of the plastic traditions of the Franciscan order, the production of visual Venetian culture, and the "conversation," in Hans Belting's sense, occurring between the Venetian artist, Andrea Mantegna and Antonello da Messina. In examining the supports, it seems that Giovanni Bellini wanted to create his own miraculous image that would prepare a sacremental rite for the gaze in which the painter would be the sacerdote. 
INDEX

Index géographique : Italie

Keywords : Altarpiece, unction, frame, sacramental theology, devotional practices, icons. Index chronologique : XVe siècle

Mots-clés : Retable, cadre, onction, encadrement, théologie sacramentelle, pratiques dévotionnelles, icônes.

\section{AUTEUR}

\section{VICKI-MARIE PETRICK}

EHESS

Vicki-Marie Petrick vient de terminer sa thèse, Marie-Madeleine dans la peinture italienne du Duecento à Titien, sous la direction, à l'origine, de Daniel Arasse et achevée sous celle de Sylvain Piron. Elle s'intéresse aux sens des matières et de la facture, à la "higher iconology" que décrit David Rosand, au corps, surtout féminin, aussi bien qu'à l'histoire immédiatiste selon David Hackett Fisher. Ses communications récentes : Intervention au séminaire de Sylvain Piron et Emanuele Coccia, EHESS : « L'arrière-plan alchimique des vitraux de la chapelle de la Madeleine d'Assise ", 10 janvier 2012. Intervention au séminaire collectif d'Alain Boureau, Béatrice Delaurenti et Sylvain Piron : «La Pala della Maddalena : entre lecture olivienne et fin'amor», 14 mars 2012. 